\title{
Characterization and comparative analysis of transcriptional profiles of porcine colostrum and mature milk at different parities
}

Brittney N. Keel ${ }^{*}$ D, Amanda K. Lindholm-Perry, William T. Oliver, James E. Wells, Shuna A. Jones and Lea A. Rempel

\begin{abstract}
Background: Porcine milk is a complex fluid, containing a myriad of immunological, biochemical, and cellular components, made to satisfy the nutritional requirements of the neonate. Whole milk contains many different cell types, including mammary epithelial cells, neutrophils, macrophages, and lymphocytes, as well nanoparticles, such as milk exosomes. To-date, only a limited number of livestock transcriptomic studies have reported sequencing of milk. Moreover, those studies focused only on sequencing somatic cells as a proxy for the mammary gland with the goal of investigating differences in the lactation process. Recent studies have indicated that RNA originating from multiple cell types present in milk can withstand harsh environments, such as the digestive system, and transmit regulatory molecules from maternal to neonate. Transcriptomic profiling of porcine whole milk, which is reflective of the combined cell populations, could help elucidate these mechanisms. To this end, total RNA from colostrum and mature milk samples were sequenced from 65 sows at differing parities. A stringent bioinformatic pipeline was used to identify and characterize 70,841 transcripts.
\end{abstract}

Results: The 70,841 identified transcripts included 42,733 previously annotated transcripts and 28,108 novel transcripts. Differential gene expression analysis was conducted using a generalized linear model coupled with the Lancaster method for $P$-value aggregation across transcripts. In total, 1667 differentially expressed genes (DEG) were identified for the milk type main effect, and 33 DEG were identified for the milk type x parity interaction. Several gene ontology $(\mathrm{GO})$ terms related to immune response were significant for the milk type main effect, supporting the well-known fact that immunoglobulins and immune cells are transferred to the neonate via colostrum.

Conclusions: This is the first study to perform global transcriptome analysis from whole milk samples in sows from different parities. Our results provide important information and insight into synthesis of milk proteins and innate immunity and potential targets for future improvement of swine lactation and piglet development.

Keywords: RNA-Seq, Transcriptome, Milk, Colostrum, Total RNA, Gene expression, Long non-coding RNA, Lancaster method

\footnotetext{
* Correspondence: brittney.keel@usda.gov

Mention of a trade name, proprietary product, or specified equipment does not constitute a guarantee or warranty by the USDA and does not imply approval to the exclusion of other products that may be suitable.

The USDA is an equal opportunity provider and employer.

USDA-ARS Roman L Hruska US Meat Animal Research Center, Clay Center, NE 68933, USA
}

(c) The Author(s). 2021 Open Access This article is licensed under a Creative Commons Attribution 4.0 International License, which permits use, sharing, adaptation, distribution and reproduction in any medium or format, as long as you give appropriate credit to the original author(s) and the source, provide a link to the Creative Commons licence, and indicate if changes were made. The images or other third party material in this article are included in the article's Creative Commons licence, unless indicated otherwise in a credit line to the material. If material is not included in the article's Creative Commons licence and your intended use is not permitted by statutory regulation or exceeds the permitted use, you will need to obtain permission directly from the copyright holder. To view a copy of this licence, visit http://creativecommons.org/licenses/by/4.0/. The Creative Commons Public Domain Dedication waiver (http://creativecommons.org/publicdomain/zero/1.0/) applies to the data made available in this article, unless otherwise stated in a credit line to the data. 


\section{Background}

Colostrum and milk play a key role in survival and growth of the neonate, providing essential nutrients and antibodies [1]. Langer et al. [2] investigated differences in composition of colostrum and mature milk in several eutherian species and found that in some species colostrum contains higher concentrations of proteins than mature milk, and in other species the fluids have similar composition. These differences are likely due to speciesspecific strategies for immunoglobulin transfer, i.e. prenatal transfer via placenta or yolk sac versus postnatal transfer via colostrum [2]. The critical importance of colostrum and milk for the newborn piglet has been well-documented [1, 3].

Piglet growth and survival are critical to the swine industry. Progeny born to primiparous sows (gilts) are born lighter, grow slower, and have higher mortality rates than those born to multiparous sows $[4,5]$. It has been hypothesized that differences in lifetime performance between gilt progeny and sow progeny may be due to differences in lactation performance, specifically lower levels of immunoglobulin G (IgG) and other energetic components in the colostrum and milk of gilts. However, data from Craig et al. [6] showed no parity differences in total IgG, fat, protein, lactose, and net energy concentrations. These results suggest that the poorer performance of gilt progeny is unlikely due to insufficient nutrient levels and is more likely due to differences in colostrum and milk intake and their ability to digest and absorb each component [5].

The presence of many different ribonucleic acid (RNA) types, including messenger RNA (mRNA), micro RNA (miRNA), long non-coding RNA (lncRNA), and circular RNA (circRNA) has been documented in milk from several mammalian species [7-12]. In fact, the total RNA concentration in human breast milk was higher than in other body fluids [8]. Whole milk contains many different cell types, including mammary epithelial cells (MEC), neutrophils, macrophages, and lymphocytes [7, 13], as well nanoparticles, such as milk exosomes [14]. Products from exosomes can withstand harsh environments such as the digestive system and allow for transmission of regulatory molecules (e.g., miRNA) from maternal to neonate [15-17]. Additionally, mRNA that are resistant to acidic conditions and RNase treatments have been identified in bovine milk [15, 18].

A limited number of livestock transcriptomic studies have reported sequencing of milk, including two in swine $[19,20]$, three in cattle [21-23], one in goat [24], one in sheep [25], and one in buffalo [26]. The emphasis of these studies was gene expression related to the lactation process, and as such, milk somatic cells were sequenced as a proxy for the mammary gland tissue. Additionally, the RNA repertoire derived from milk exosomes has been reported in cattle [11, 27] and swine $[12,28]$. To our knowledge, there have been no studies that have reported direct sequencing of porcine whole milk samples.

As the only nutritional source for newborn piglets, porcine colostrum and milk contain critical nutritional and immunological components, including carbohydrates, lipids, and immunoglobulins, as well as exosomes, oligosaccharides, and bacteria, which possibly act as biological signals and modulate the intestinal environment and immune status later in life [29]. As part of an effort to explore the transcriptomic profile of the piglet's neonatal diet, we performed total RNAsequencing (total RNA-Seq) on porcine whole milk samples (colostrum and mature milk) from dams in parities one through four to characterize and compare the two transcriptomes. We identified novel mRNA and lncRNA transcripts and quantified expression of both known and novel porcine transcripts. Expression profiles were compared to identify differentially expressed genes (DEG) between colostrum and mature milk between parities.

\section{Results}

\section{High-throughput sequencing}

RNA-Seq libraries were sequenced generating over 6 billion 75 base pair (bp) paired-end reads, with an average of 46.2 million reads per library (Table S1). The number of reads in the colostrum libraries ranged from 22.6 to 81.8 million reads with an average of 44.4 million reads, while the number of reads in the mature milk libraries ranged from 24.2 to 97.8 million reads with an average of 48.0 million reads. After adapter removal and read trimming, the resulting high-quality reads were mapped to the Sscrofa 11.1 genome assembly with an average 99.6\% read mapping rate per library. The number of reads aligning to known mRNA, miscellaneous RNA (miscRNA; short non-coding RNA), non-coding RNA (ncRNA), and pseudogenes in the swine genome are presented in Table S2. It was observed that $\sim 50 \%$ of reads mapped to known mRNA, while $50.5 \%$ of colostrum reads and $44.5 \%$ of milk reads were mapped outside of annotated loci, potentially harboring novel transcripts (Fig. 1).

\section{Transcript identification and characterization}

Transcripts, assembled individually for each library, were merged into a single set of 460,853 putative transcripts. This set was subjected to several filtering steps to remove transcriptional noise and classify transcripts (Fig. 2). Transcripts identified in only one library and lowly expressed transcripts were removed, as these were considered transcriptional noise. The remaining set of transcripts was filtered to include only those with class 


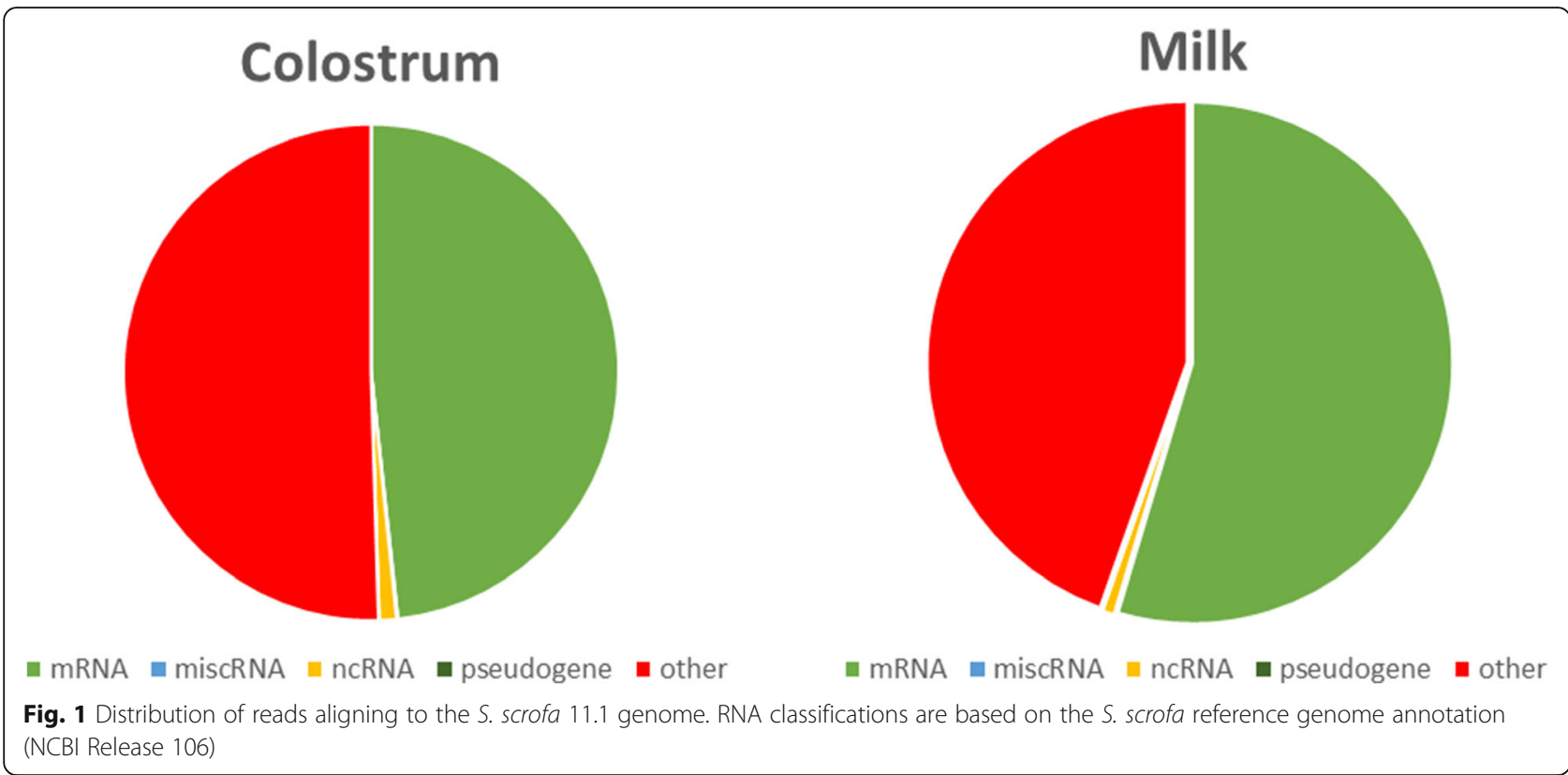

codes '=', ' $u$ ', ' $x$ ', ' $j$ ', and 'i' (Figure S1). The transcripts with class codes ' $u$ ', ' $x$ ', ' $j$ ', and ' $i$ ' were further filtered by length, and number of exons. This set of 38,164 putative novel transcripts were then subjected to classification by open reading frame (ORF) length and protein coding potential score to complete transcript characterization. In total, 70,841 transcripts were identified in the porcine milk transcriptome, including 42,733 previously annotated transcripts as well as 28,108 novel transcripts.

Genomic coordinates of the identified novel transcripts are given in Tables S3 and S4. Among the novel lncRNA transcripts, 256 and 175 were intergenic long non-coding RNA (lincRNA) and intronic long noncoding RNA (ilncRNA), respectively, while 305 lncRNA flanked a protein-coding gene in a divergent orientation (long non-coding natural antisense transcripts; lncNAT) and 566 were novel isoform long non-coding RNA (isolncRNA) (Fig. 3A). Using the BLAST algorithm, a total of 578 lncRNA exhibited homology with transcripts in the porcine NONCODE database, 146 lncRNA exhibited homology with non-coding transcripts in other species, and 225 lncRNA were homologous to noncoding transcripts in both swine and other species (Fig. 3B; Table S5). A similar analysis identified that 26,582 of the novel mRNA transcripts were homologous to known transcripts in swine and other species (Fig. 4).

Basic sequence features of the novel transcripts, including length, exon number, expression, and ORF length, are shown in Fig. 5 and Table 1. Novel lncRNA were significantly shorter and expressed at lower levels than novel mRNA and known transcripts (Fig. 5A, B). The exon number of the novel lncRNA and coding transcripts were notably smaller than that of known transcripts (Fig. 5C). The ORF length of novel lncRNA was significantly shorter than ORF length in known and novel coding transcripts, while the ORF length of novel coding transcripts was significantly shorter than that of known transcripts (Fig. 5D).

Transcripts corresponded to 17,910 unique gene loci, of which 17,296 genes were previously annotated in the $S$. scrofa reference genome. Previously annotated transcripts corresponded to 16,992 known gene loci, while unannotated protein-coding and non-coding transcripts corresponded to 8384 (7933 known) and 1059 (843 known) loci, respectively. In general, gene expression values were widely distributed (Fig. 6), with the distributions of gene expression values being approximately equal for colostrum and mature milk. There was a large overlap (19 out of 25) in the top twenty-five most abundantly expressed genes in colostrum and mature milk (Table 2; Fig. 7).

\section{Expression of cell-specific markers}

Whole milk is a complex fluid containing a heterogenous mixture of cells [30,31]. Analysis of gene expression of cell-specific markers, the same markers utilized in [32], was used to estimate the proportion of various cell types present in colostrum and mature milk samples (Table 3; Fig. 8). Epithelial cells were the most abundant cells in all samples, with higher abundance in mature milk samples. Stromal cells represented $\sim 1 \%$ of the cell population in all samples. Immune cells and stromal cells were both more abundant in colostrum samples. 


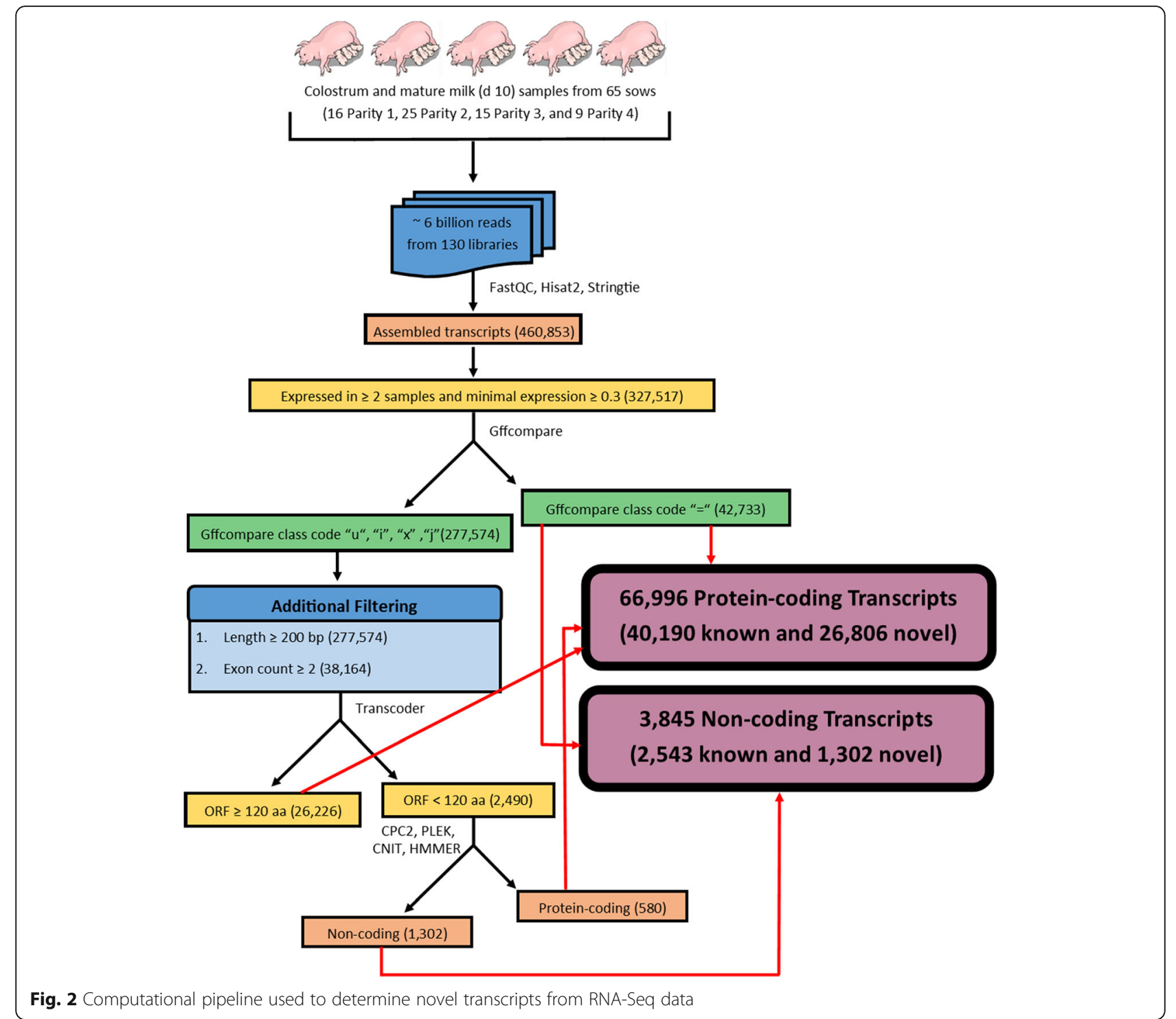

PCA and differential expression analysis

The principal component analysis (PCA) plot (Fig. 9) showed that colostrum and mature milk transcript expression profiles seem to fall into distinct clusters, while there was no clear clustering of samples by parity. After multiple testing correction, we identified 169 differentially expressed transcripts (DET) for the milk type $\mathrm{x}$ parity interaction, $4783 \mathrm{DET}$ for the milk type main effect, and 9639 DET for the parity main effect (Tables S6, S7 and S8). Table 4 shows the classifications of DET. The DET set for the milk type main effect was comprised of 2479 known transcripts, 2132 novel coding transcripts, and 172 novel lncRNA, while the interaction DET set included 85 known transcripts and 80 and 4 novel coding transcripts and lncRNA, respectively. The 25 most significant DET for milk type and interaction are given in Tables 5 and 6 , respectively. $P$-values of transcripts were aggregated for each gene loci to obtain DEG. A total of 1667 DEG were identified for the milk type main effect, and 33 DEG were identified for the milk type $\mathrm{x}$ parity interaction (Tables S9 and S10).

\section{Gene ontology and pathway analysis}

Gene ontology (GO) analysis of the DEG indicated that genes associated with the milk type main effect were predominantly involved in binding (37.5\%), catalytic activity (30.5\%), molecular function regulation (15.8\%), and transporter activity (8.2\%). A total of 250 biological process, 25 molecular function, and 54 cellular component GO terms were significantly enriched in this gene set (Table S11). Additionally, 3 KEGG pathways were significantly enriched.

Like the milk type main effect genes, DEG for the milk type $\mathrm{x}$ parity interaction were involved in binding (45.5\%), 
$\mathbf{A}$

\section{LncRNA Classifications}

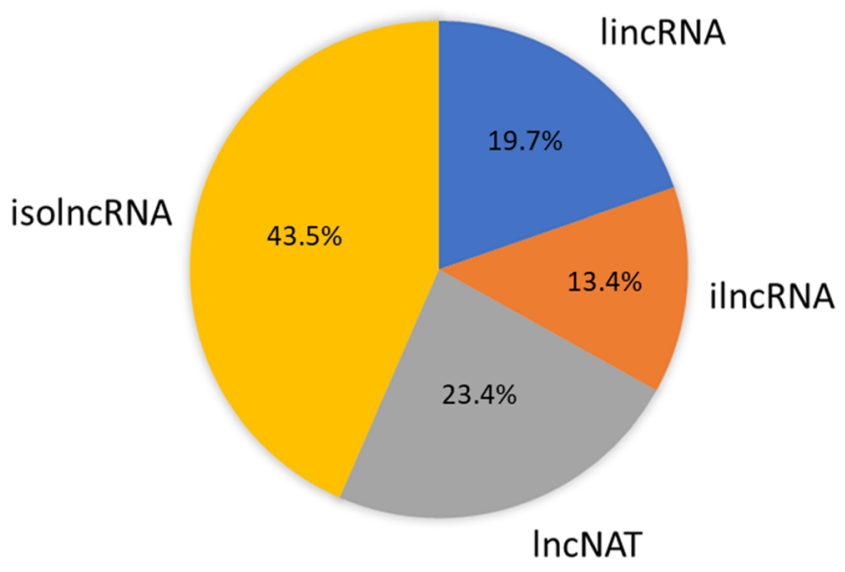

B Overlap With NONCODE Database

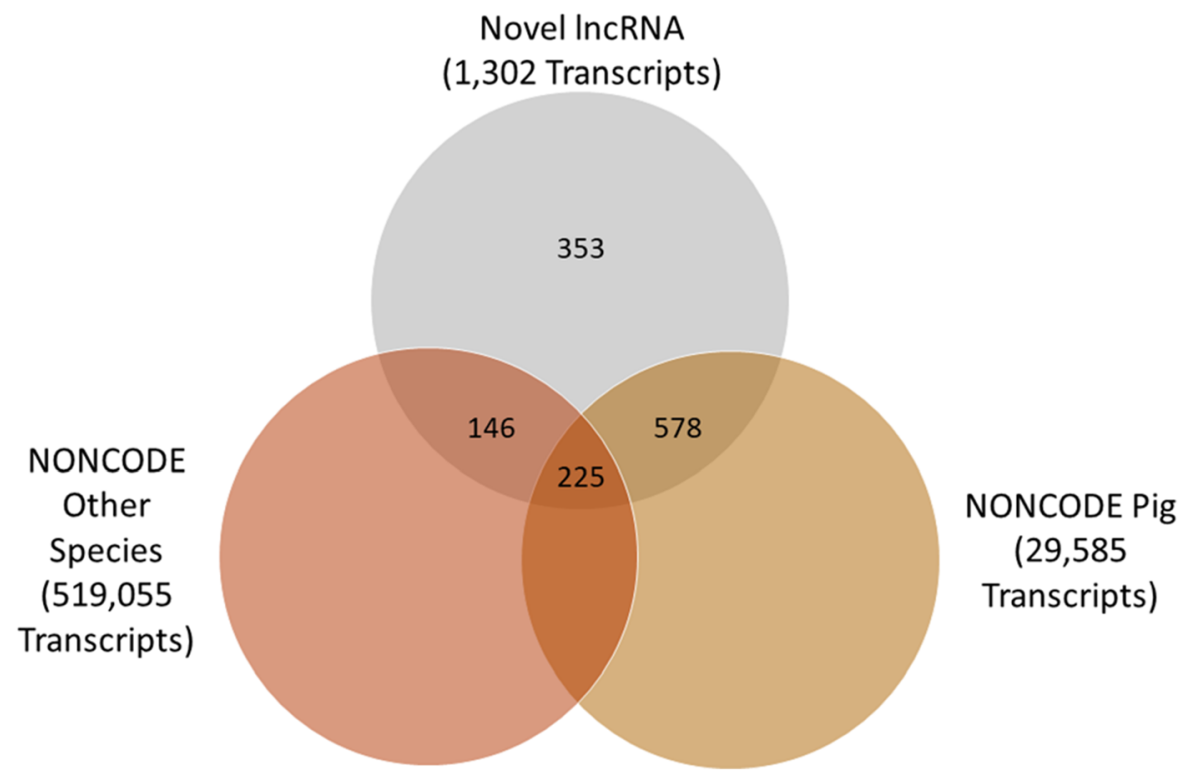

Fig. 3 Classification of novel IncRNA In (A) lincRNA denotes intergenic long-noncoding RNA, ilncRNA denotes intronic long-noncoding RNA, IncNAT denotes long non-coding antisense transcripts, and isolncRNA denotes novel isoform long non-coding RNA

catalytic activity (27.3\%), molecular adapter activity (9.1\%), molecular function regulation (9.1\%), and transporter activity (9.1\%). No GO terms or pathways were significantly enriched in this DEG set.

\section{Discussion}

Milk production, milk composition, milk intake, and milk digestibility are all major limiting factors in the growth and survival of a sow's litter. Knowledge of porcine milk composition, as well as understanding genetic factors underlying its variation, is a matter of ongoing interest. In this study, we performed the first exhaustive characterization of the porcine milk transcriptome derived from whole milk samples. The goal was to characterize and compare transcriptomic profiles of samples collected during early and mid-lactation from dams across different parities. This study was the first in a series of studies aimed at exploring the molecular profile of the piglet's neonatal diet.

Total RNA was isolated from 130 fresh whole milk samples (65 colostrum and 65 mature milk) from dams across four parities. In most milk transcriptome studies, 


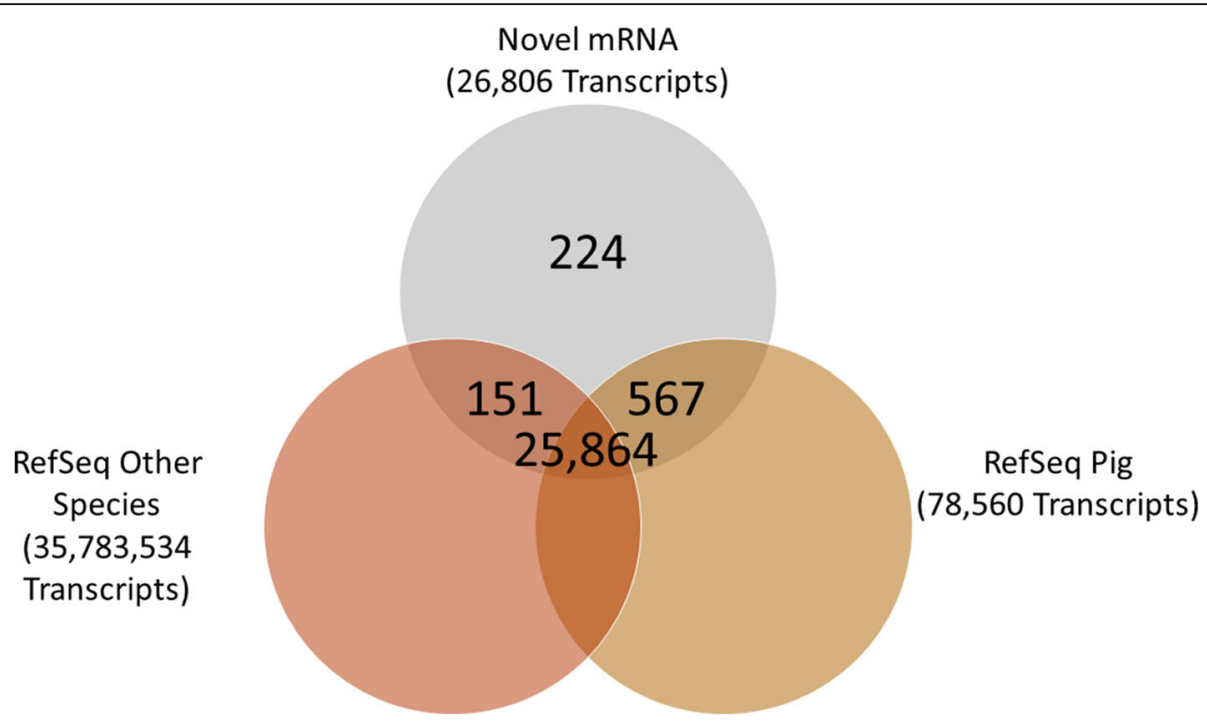

Fig. 4 Overlap of novel protein-coding transcripts with RefSeq database

milk is fractionated, and RNA is extracted from somatic cells, milk fat, or whey. Total RNA concentrations tend to be higher in the milk fat and somatic cells than in the whey fraction, while RNA integrity of somatic cells is higher than those of milk fat and whey [33, 34]. Low RIN values in this study (average $\mathrm{RIN}=4.0$ ) are likely due to the presence of small amounts of cytoplasmic material in milk fat globules [35], bacteria and small RNA (miRNA) in the fat fraction [36], and degraded and/or free RNA. Each milk fraction has its own place in research settings. The advantages and disadvantages of each RNA source has previously been summarized [32] In this study, we chose to utilize whole milk samples in order to capture the broader transcriptomic signatures

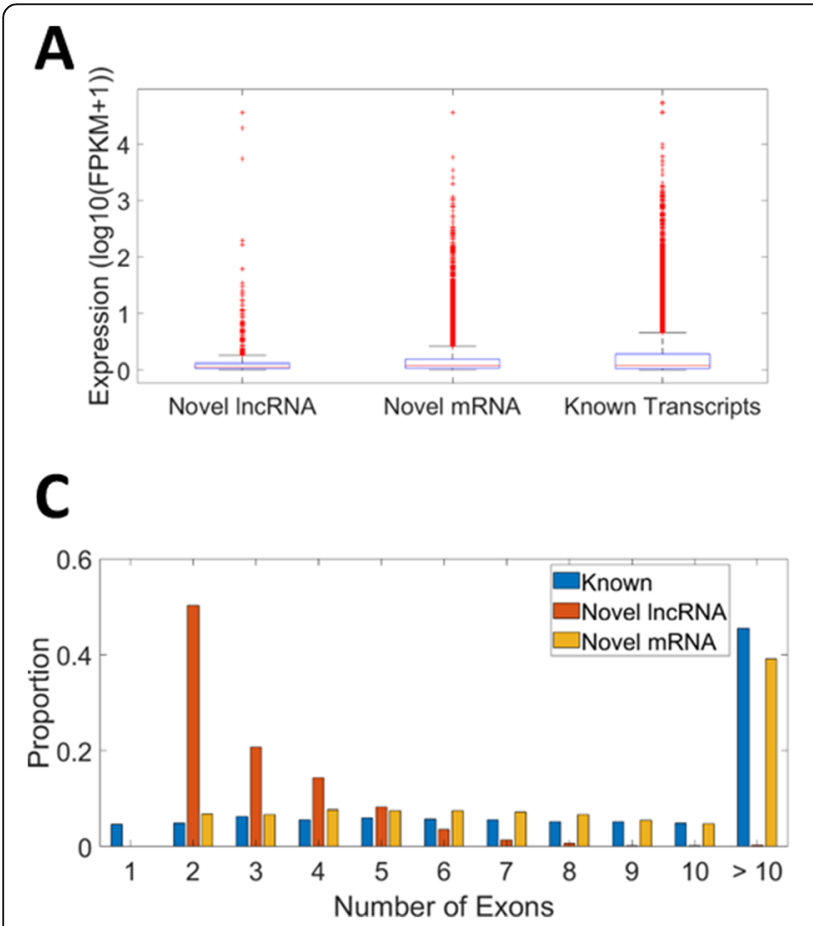

B

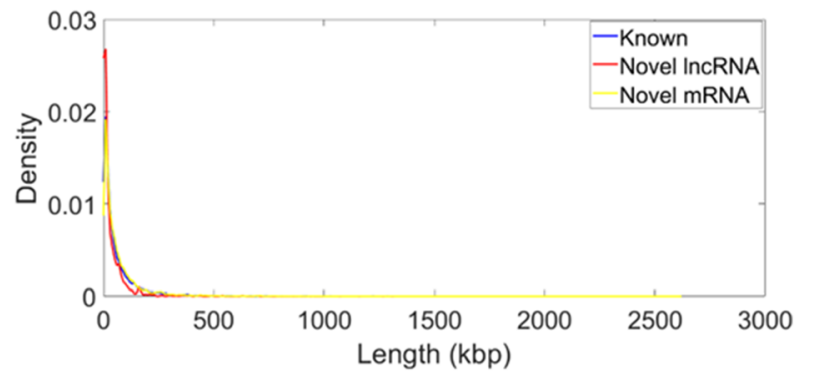

D

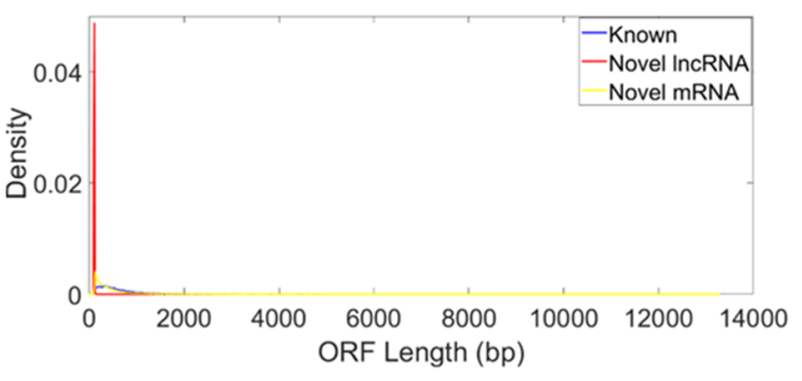

Fig. 5 Basic features of transcripts. A Expression level of transcripts. B Length distribution of transcripts. C Number of exons for transcripts. D ORF length distribution of transcripts 
Table 1 Median characteristics of expressed transcripts

\begin{tabular}{llll}
\hline & Novel IncRNA & Novel Coding & Known Transcripts \\
\hline Expression $^{\mathrm{a}}$ & $0.06^{\mathrm{d}, \mathrm{f}}$ & $0.09^{\mathrm{e}}$ & 0.09 \\
Length $^{\mathrm{b}}$ & $13.37^{\mathrm{e}, \mathrm{f}}$ & 34.51 & 29.25 \\
Number Exons $^{\mathrm{e}}$ & $2^{\mathrm{e}} \mathrm{f}$ & $8^{\mathrm{e}}$ & 10 \\
ORF Length $^{\mathrm{c}}$ & $109^{\mathrm{e}, \mathrm{f}}$ & $332^{\mathrm{e}}$ & 481 \\
\hline
\end{tabular}

${ }^{a}$ Measured in $\log _{10}($ FPKM+1)

b Measured in kbp

c Measured in bp

e Left-tailed Wilcoxon rank-sum $P$-value $<0.05$ compared to known transcripts

${ }^{f}$ Left-tailed Wilcoxon rank-sum $P$-value $<0.05$ compared to novel coding

of porcine colostrum and milk. We were able to process the samples much more quickly than had we fractionated the milk, and our sample represents the entirety of what is being ingested by the growing piglet.

Libraries were sequenced to an average depth of 46 million reads per library. A depth of 40 million reads is considered sufficient for reliable detection of major splice isoforms for abundant and moderately abundant transcripts [37]. When generating our sequence data, we targeted a depth of 50 million reads per library. However, there was considerable variation in sequence depth across libraries. Some of this variation can be attributed to technical aspects of next-generation sequencing (NGS) technology, such as the stochasticity of sequencing, RNA quality, and library preparation.

A total of 70,841 transcripts were identified in this study, of which approximately $60 \%$ are annotated in the current swine genome build. Transcripts corresponded to 17,910 unique gene loci, including 17,296 known porcine genes. The number of expressed genes is comparable to those reported in similar studies in sheep [25] and goat [24]. A smaller number of expressed genes ( 13,500) was reported in the buffalo milk transcriptome [26]. This discrepancy is likely to due to the swine, sheep, and goat reference genomes being more complete and of higher quality.

As expected, cells in our whole milk samples appeared to be a heterogeneous population of immune, epithelial, stromal, and stem cells (Table 3; Fig. 8). Epithelial cells represented the largest subset of the cell population in all samples, on average $85 \%$ of the cell population per sample. This is consistent with findings in bovine milk [31]. Immune cells were the second most abundant cell type, comprising an average of 14 and $9 \%$ the colostrum and mature milk cell populations, respectively. In general, stromal cells were more highly expressed in colostrum. In particular, adipocytes (characterized by the FABP4 marker) accounted for nearly $2 \%$ of colostrum cell populations. Adipocytes release the hormone leptin in the presence of insulin, which is present in colostrum and mature milk. Previous studies have shown a decrease in leptin concentration in milk across lactation stages in swine [38], human [39], and cattle [40]. Hemopoietic stem cells accounted for approximately $1 \%$ of the cell population in both colostrum and mature milk, differing from findings in human where hemopoietic stem cells were significantly higher in mature milk compared to colostrum [41].

Previous milk transcriptome studies in livestock have used sequencing of milk somatic cells as a proxy for the mammary gland to study the lactation process. Recent studies have indicated that RNA originating from multiple cell types present in milk can withstand harsh environments, such as the digestive system, and transmit regulatory molecules from maternal to neonate [15-17]. Hence, transcriptome profiling of whole milk samples, which is reflective of the combined cell populations, is needed to understand these mechanisms. Most of the stable, bioactive RNA in milk reported in the literature has been miRNA [17]. However, stable mRNA, alpha S2-casein (CSN1S2), beta-casein (CSN2), and beta-

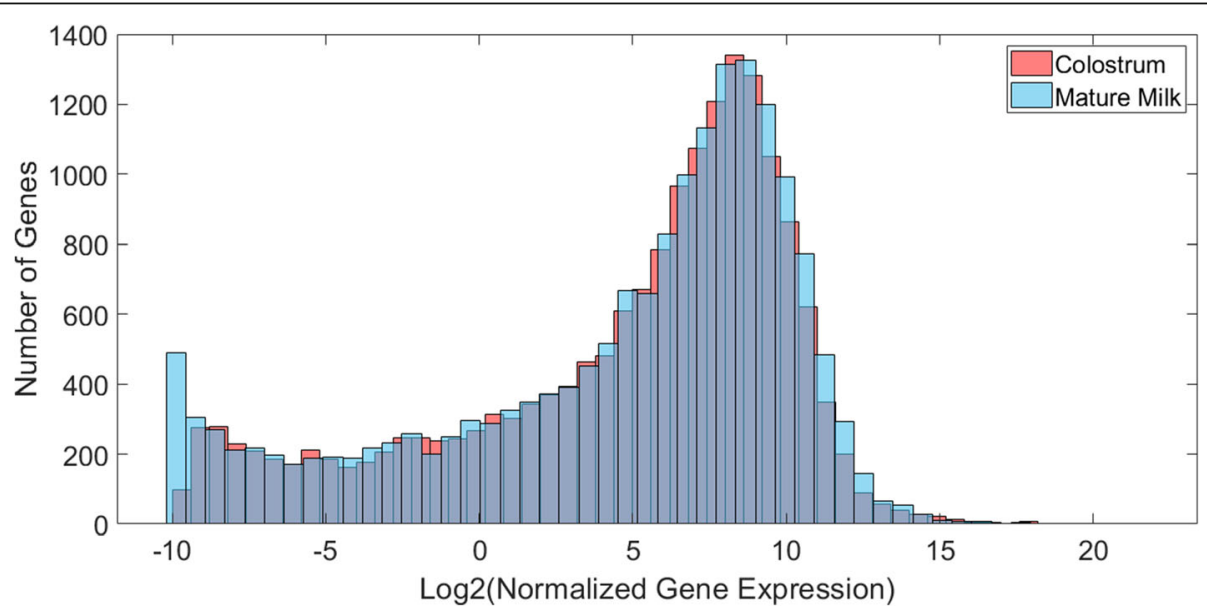

Fig. 6 Plot of gene expression distribution for colostrum and mature milk samples. Values are averaged across samples in each group 
Table 2 Top expressed genes in porcine colostrum and mature milk

\begin{tabular}{|c|c|c|c|}
\hline Gene Symbol & Description & Colostrum $^{\mathrm{a}}$ & Mature Milk ${ }^{a}$ \\
\hline LOC110258600 & Basic salivary proline-rich protein 2-like & $28.49(1)$ & $8.33(7)$ \\
\hline MIR9816 & Uncharacterized ncRNA & $18.39(2)$ & $5.30(8)$ \\
\hline PAEP & Progestagen associated endometrial protein & $10.85(3)$ & $15.01(3)$ \\
\hline LOC102158335 & Uncharacterized ncRNA & $7.77(4)$ & $1.77(15)$ \\
\hline LOC110258215 & Progesterone receptor-like & $6.10(5)$ & $1.87(12)$ \\
\hline LOC110258214 & Basic salivary proline-rich protein 4-like & $5.83(6)$ & $0.712(29)$ \\
\hline CYTB & Cytochrome b & $5.46(7)$ & $1.05(22)$ \\
\hline MSTRG.27426 & Novel mRNA & $4.06(8)$ & $9.49(6)$ \\
\hline NEMF & Nuclear export mediator factor & $3.74(9)$ & $9.81(5)$ \\
\hline CSN3 & Casein kappa & $3.65(10)$ & $29.90(2)$ \\
\hline DIABLO & Diablo IAP-binding mitochondrial protein & $3.38(11)$ & $1.10(21)$ \\
\hline LOC100737553 & Peptidyl-prolyl cis-trans isomerase A pseudogene & $3.20(12)$ & $44.80(1)$ \\
\hline EEF1A1 & Eukaryotic translation elongation factor 1 alpha 1 & $2.98(13)$ & $1.83(14)$ \\
\hline CSN1S1 & Casein alpha s1 & $2.54(14)$ & $12.12(4)$ \\
\hline LOC102163473 & Uncharacterized ncRNA & $1.96(15)$ & $0.58(? ?)$ \\
\hline $\mathrm{XDH}$ & Xanthine dehydrogenase & $1.35(16)$ & $1.86(13)$ \\
\hline TPT1 & Tumor protein, translationally-controlled 1 & $1.34(17)$ & $1.12(20)$ \\
\hline PDE4D & Phosphodiesterase 4D & $1.19(18)$ & $0.25(49)$ \\
\hline FASN & Fatty acid synthase & $1.05(19)$ & $1.27(18)$ \\
\hline FABP3 & Fatty acid binding protein 3 & $0.94(20)$ & $1.35(16)$ \\
\hline ICK & Ciliogenesis associated kinase 1 & $0.87(21)$ & $1.25(19)$ \\
\hline CSN2 & Casein beta & $0.82(22)$ & $2.13(11)$ \\
\hline RPLPO & Ribosomal protein lateral stalk subunit P0 & $0.82(23)$ & $0.36(41)$ \\
\hline EEF2 & Eukaryotic translation elongation factor 2 & $0.78(24)$ & $0.42(38)$ \\
\hline RPL4 & Ribosomal protein L4 & $0.63(25)$ & $0.30(42)$ \\
\hline LALBA & Lactalbumin alpha & $0.36(49)$ & $4.54(9)$ \\
\hline SAA3 & Serum amyloid A-3 protein & $0.25(76)$ & $2.30(10)$ \\
\hline POLE2 & DNA polymerase epsilon 2, accessory subunit & $0.57(27)$ & $1.35(17)$ \\
\hline PIGR & Polymeric immunoglobulin receptor & $0.11(148)$ & $1.00(23)$ \\
\hline PLIN2 & Perilipin 2 & $0.06(257)$ & $0.89(24)$ \\
\hline ACSL3 & Acyl-CoA synthetase long chain family member 3 & $0.13(132)$ & $0.87(25)$ \\
\hline
\end{tabular}

${ }^{a}$ Average normalized gene expression value $\left(\times 10^{5}\right)$ across samples. Number in parenthesis is ranking in expressed genes

lactoglobin (BLG), have been reported in cattle [16]. These three mRNA were also found to be expressed in both colostrum and mature milk samples in this study. Additional studies are needed to confirm whether these mRNA can function in the piglet gastrointestinal tract.

Among the top expressed genes were CSN3, CSN2, CSN1S1, LALBA, FASN, EEF1A1, PAEP, TPT1, FABP3, $X D H, P I G R$, and SAA3 (Table 2; Fig. 7), which have been previously identified among the top expressed genes in milk samples from other species [10, 24-26, 42]. As expected, many of the top expressed genes were related to biosynthesis of milk proteins. Expression levels of CSN2, CSN3, CSN1S1, LALBA, and PAEP, which encode for the synthesis of the main milk proteins casein and whey, increased from early to mid-lactation stages. A similar gene expression pattern has been identified in a previous swine study [43], as well as in goat [24], cattle [42], and sheep [25]. High expression of the EEF1A1 gene is also related to high levels of milk protein synthesis, as EEF1A1 is one of the most abundant protein synthesis factors [24]. Consistent with results in buffalo [26], ribosomal protein RPLPO was among the top expressed genes in colostrum and exhibited a slight decrease in expression during mid-lactation.

In addition to milk protein synthesis genes, genes associated with milk fat were among the top expressed 


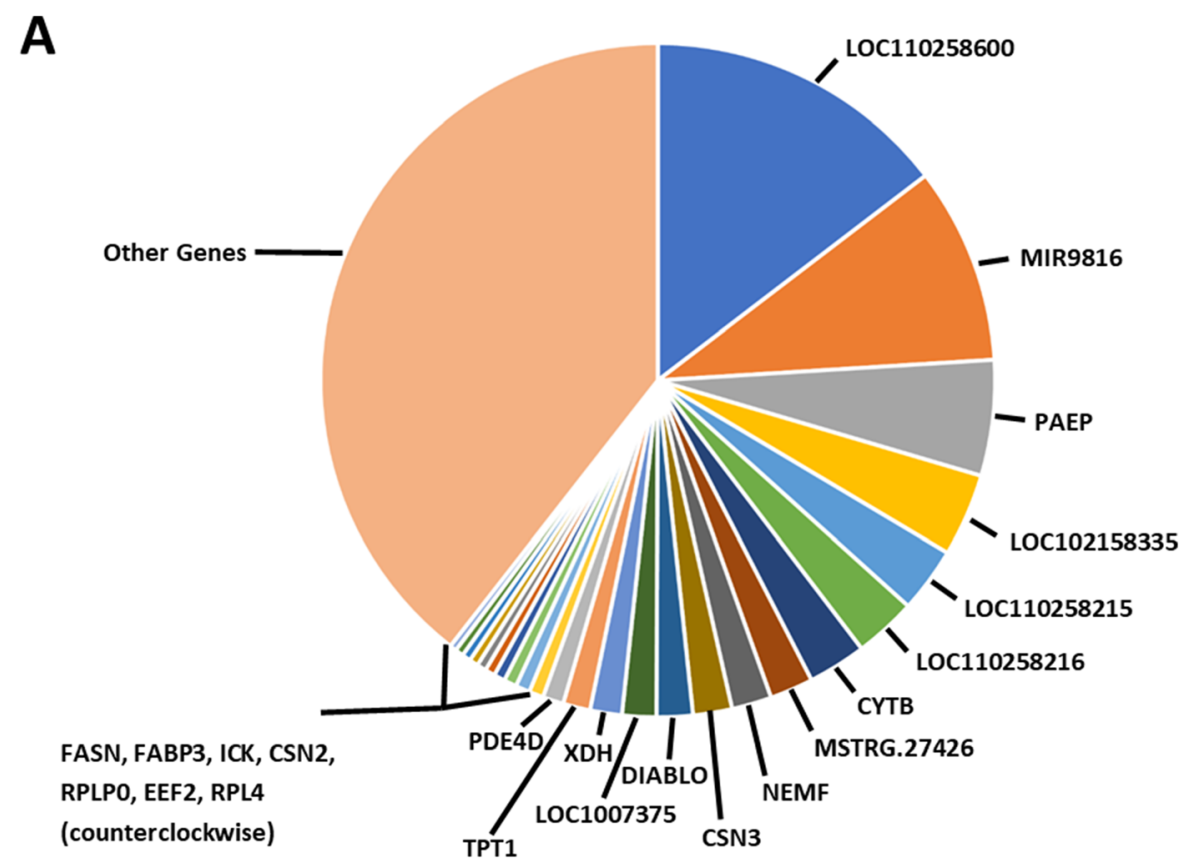

B

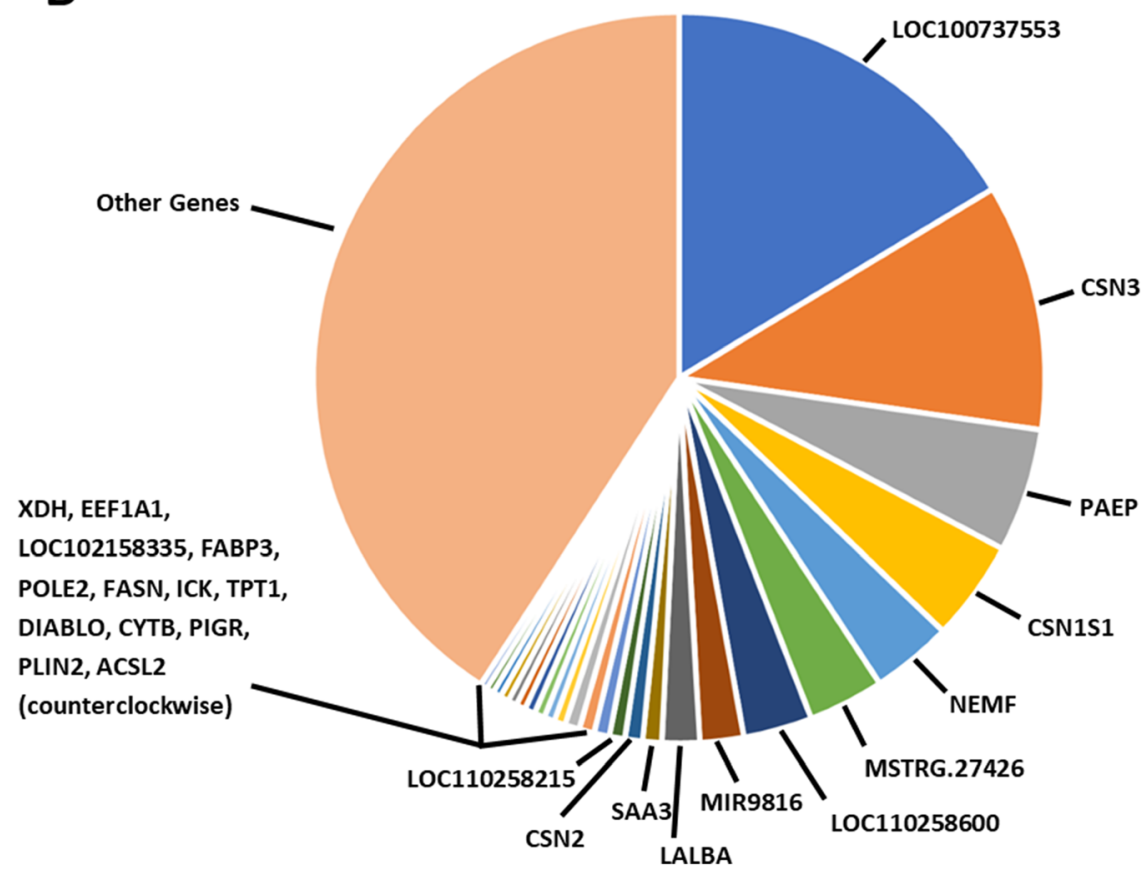

Fig. 7 Relative gene abundances of highest expressed genes in $\mathbf{A}$ colostrum and $\mathbf{B}$ mature milk samples

genes, and their expression increased from early to midlactation. Milk fat composition is known to influence piglet growth and development [44]. The FABP3 gene, which is involved in the uptake and transport of fatty acids, has been linked to milk fat synthesis in cattle [45].
FASN is directly involved in most of the short and medium-chain fatty acids in milk [46], and PLIN2 is involved in the formation of the lipid droplet in milk [47].

DET were determined for the milk type by parity interaction, as well as both the milk type and parity main 
Table 3 Average proportion of cell types in colostrum and mature milk samples

\begin{tabular}{|c|c|c|c|c|c|c|c|c|}
\hline Cell Type & $\begin{array}{l}\text { P1 } \\
\text { Col. }\end{array}$ & $\begin{array}{l}\text { P2 } \\
\text { Col. }\end{array}$ & $\begin{array}{l}\text { P3 } \\
\text { Col. }\end{array}$ & $\begin{array}{l}\text { P4 } \\
\text { Col. }\end{array}$ & $\begin{array}{l}\text { P1 } \\
\text { Milk }\end{array}$ & $\begin{array}{l}\text { P2 } \\
\text { Milk }\end{array}$ & $\begin{array}{l}\text { P3 } \\
\text { Milk }\end{array}$ & $\begin{array}{l}\text { P4 } \\
\text { Milk }\end{array}$ \\
\hline Pan- Immune (PTPRC) & 0.100 & 0.136 & 0.088 & 0.112 & 0.087 & 0.134 & 0.037 & 0.056 \\
\hline Immune (CD8A) & 0.001 & 0.007 & 0.002 & 0.011 & 0.001 & 0.000 & 0.001 & 0.000 \\
\hline Immune (NCAM1) & 0.002 & 0.018 & 0.003 & 0.052 & 0.000 & 0.000 & 0.000 & 0.000 \\
\hline Immune (CD19) & 0.000 & 0.000 & 0.000 & 0.000 & 0.000 & 0.000 & 0.000 & 0.000 \\
\hline Immune (CD4) & 0.001 & 0.001 & 0.000 & 0.012 & 0.000 & 0.000 & 0.000 & 0.000 \\
\hline Immune (CD3E) & 0.001 & 0.003 & 0.000 & 0.004 & 0.000 & 0.000 & 0.000 & 0.000 \\
\hline Immune (CD3D) & 0.002 & 0.004 & 0.003 & 0.006 & 0.002 & 0.002 & 0.002 & 0.001 \\
\hline Immune (CD3G) & 0.000 & 0.000 & 0.000 & 0.001 & 0.000 & 0.000 & 0.001 & 0.000 \\
\hline Stromal (FABP4) & 0.029 & 0.025 & 0.023 & 0.026 & 0.006 & 0.008 & 0.003 & 0.003 \\
\hline Stromal (SL100A4) & 0.003 & 0.002 & 0.002 & 0.002 & 0.000 & 0.000 & 0.000 & 0.000 \\
\hline Stromal (DLK1) & 0.000 & 0.001 & 0.000 & 0.003 & 0.000 & 0.000 & 0.000 & 0.000 \\
\hline Epithelial (LAMP1) & 0.333 & 0.296 & 0.295 & 0.261 & 0.177 & 0.168 & 0.172 & 0.160 \\
\hline Epithelial (EPCAM) & 0.020 & 0.236 & 0.291 & 0.294 & 0.516 & 0.449 & 0.534 & 0.558 \\
\hline Epithelial (KRT8) & 0.311 & 0.259 & 0.284 & 0.202 & 0.198 & 0.223 & 0.234 & 0.203 \\
\hline Stem (CD34) & 0.010 & 0.012 & 0.009 & 0.015 & 0.010 & 0.013 & 0.014 & 0.016 \\
\hline
\end{tabular}

${ }^{a}$ Cell-specific marker shown in parentheses

effects. DET for the parity main effect are presented for completeness (Table S8), but the discussion will be restricted to DET/DEG for the milk type main effect and milk by parity interaction, as the objective of this study was to investigate transcriptomic differences between colostrum and milk.
Several of the most significant DET were associated with genes involved in milk fat synthesis and immunity (Tables 4 and 5). Transcripts rna42732 (THRSP gene) and rna62377 (ANXA7 gene) are milk fat synthesis genes among the most significant DET. THRSP, thyroid hormone responsive, is a crucial protein for cellular de novo

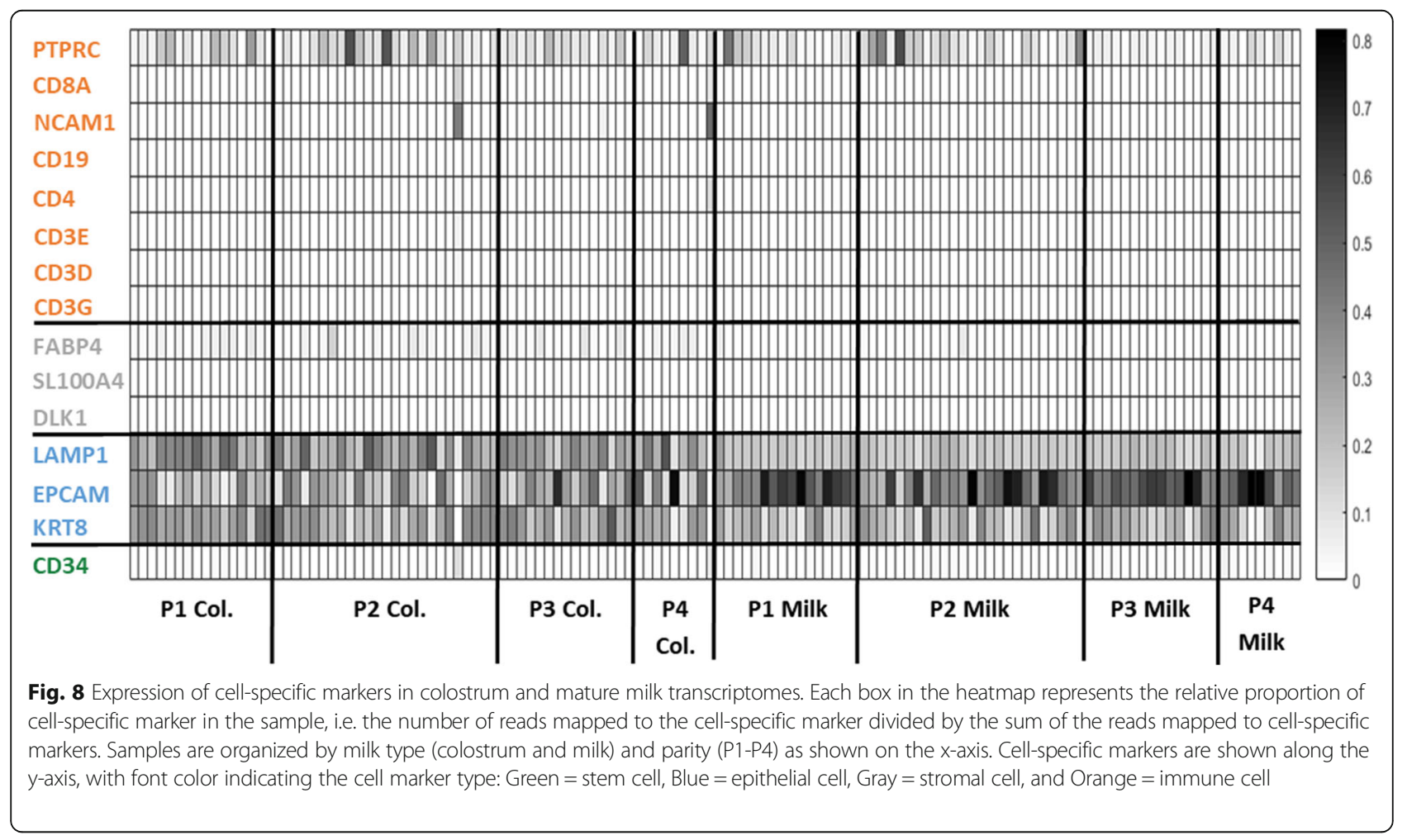




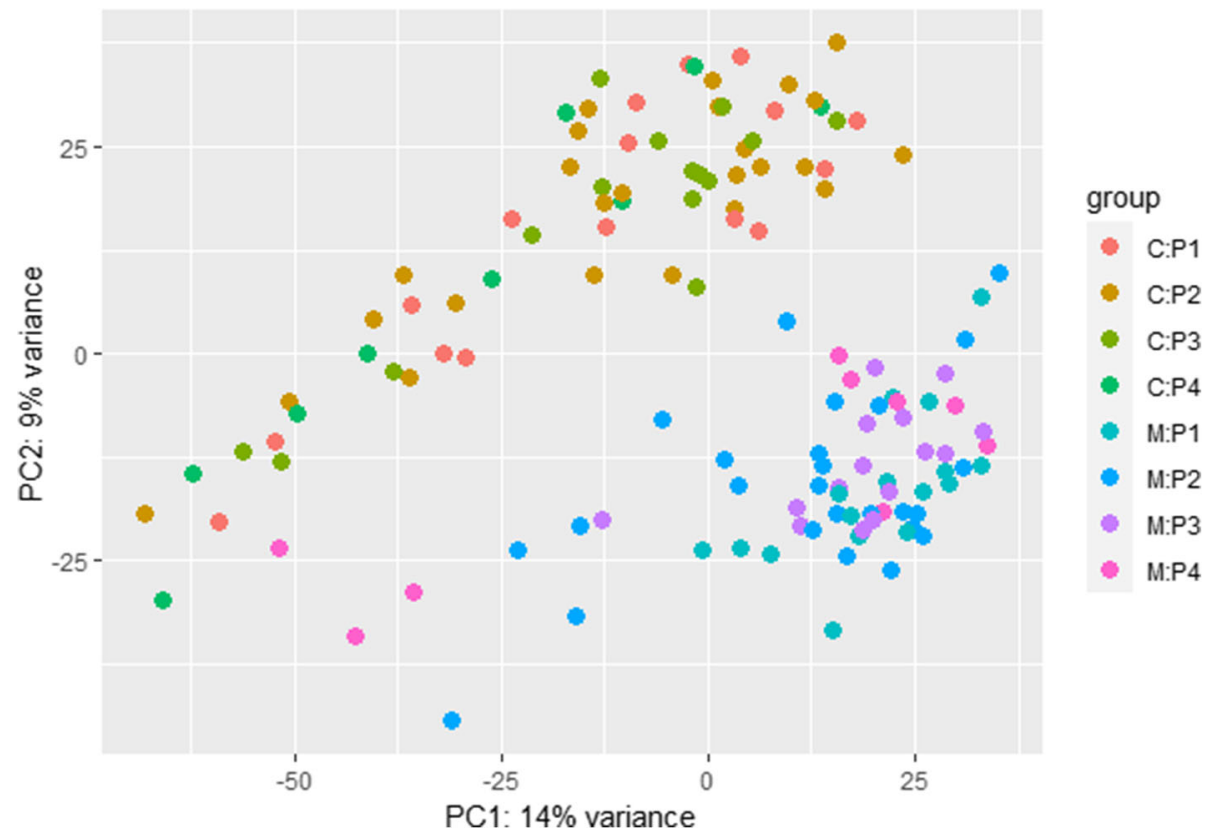

Fig. 9 PCA plot of colostrum (C) and mature milk (M) transcripts from dams in parities 1-4

lipogenesis and has been shown to play an important role in lipogenesis in the mammary epithelial cell [48, 49]. Expression of milk fat synthesis transcripts was upregulated in mature milk samples compared to colostrum, which agreed with expression patterns observed across bovine lactation stages [50]. Our results are consistent with the finding that the transition from swine colostrum to mature milk is marked by a shift from high protein contents to high fat and lactose contents [51].

Transcript rna70598, associated with the colostrum trypsin inhibitor-like gene (LOC100513767), was found to be significantly differentially expressed for the milk type main effect. Moreover, its expression was over 7fold higher in colostrum than mature milk. Trypsin secreted by the small intestine can degrade colostral antibodies, and swine immunoglobulins, such as IgG and IgA are susceptible to trypsin degradation [52]. Colostral trypsin inhibitor helps protect these immunoglobulins without preventing the digestion of other milk proteins. In addition, DET associated with granzymes GZMB (transcript rna37492) and GZMH (transcript rna37493) were among the most significant DET. Granzymes are

Table 4 Classifications of DET for milk type main effect and milk type $\mathrm{x}$ parity interaction

\begin{tabular}{lll}
\hline & Milk Type & Milk Type x Parity \\
\hline Known Transcripts & 2479 & 85 \\
Novel Coding Transcripts & 2132 & 80 \\
Novel IncRNA & 172 & 4 \\
Total & 4783 & 169 \\
\hline
\end{tabular}

serine proteases and six of the twelve members of the granzyme family (A, B, H, K, and M) have been identified in the swine genome [53]. Presence of these proteins in milk leukocytes would indicate the existence of activated or memory t-cells which are likely actively fighting pathogenic cells which may be of importance for either the infant or the protection of the mammary gland [54].

In this study, DEG were identified by aggregating $P$ values across transcripts associated with each gene via the Lancaster method, rather than using gene read counts directly. Using this approach not only maintains both transcript and gene-level resolution, but also bypasses issues of different variances and directions of change across constituent transcripts. This method outperforms other gene-level methods and provides a coherent analysis between transcripts and genes [55].

One of the major aims of this study was to evaluate DEG between lactation stages across different parities. Progeny born to multiparous sows generally exhibit superior growth performance compared to those born to primiparous sows. However, colostrum and milk composition profiles (immunoglobulin, protein, fat, lactose, and net energy) are highly similar across parities [6]. Results from this study support this finding, as very few gene expression differences were identified in the milk type by parity interaction. Only 33 DEG were identified for the milk type by parity interaction and only a clear separation in milk type was exhibited in the PCA analysis (Fig. 9).

Glucose transport is a major precursor to lactose synthesis, which is synthesized in the Golgi vesicle of 
Table 5 Twenty-five most significant DET associated with milk type. Significance was ranked using FDR-adjusted $P$-value

\begin{tabular}{|c|c|c|}
\hline Transcript & Gene & Gene Description \\
\hline rna45537 & CCDC71L & Coiled-coil domain containing 71 like \\
\hline rna5080a & ALDH1A1 & Aldehyde dehydrogenase 1 family member $\mathrm{A} 1$ \\
\hline rna54008 & KCNH8 & Potassium voltage-gated channel subfamily $\mathrm{H}$ member 8 \\
\hline rna19955 & $\mathrm{C} 4 \mathrm{H} 8 \mathrm{orf} 46$ & Vexin (VXN) \\
\hline rna70598 & LOC100513767 & Colostrum trypsin inhibitor-like \\
\hline $\operatorname{rna} 37492^{\mathrm{a}}$ & GZMB & Granzyme B \\
\hline rna42732 $2^{a}$ & THRSP & Thyroid hormone responsive \\
\hline rna8225 & LRP4 & LDL receptor related protein 4 \\
\hline MSTRG.255032.1 $1^{\mathrm{a}}$ & LOC110256328 & Uncharacterized ncRNA \\
\hline rna57086 & $\mathrm{BCHE}$ & Butyrylcholinesterase \\
\hline rna4906a & SETDB2 & SET domain bifurcated histone lysine methyltransferase 2 \\
\hline MSTRG.313167.1 ${ }^{\mathrm{b}}$ & MSTRG.313167 & Novel gene loci \\
\hline rna48308 & CALML5 & Calmodulin like 5 \\
\hline MSTRG.211924.1 ${ }^{\mathrm{b}}$ & KIF26B & Kinesin family member 26B \\
\hline rna56663 & LOC100739719 & Tetraspanin-6 \\
\hline rna16073 & SOWAHC & Sosondowah ankyrin repeat domain family member $C$ \\
\hline rna75068 & COL4A5 & Collagen type IV alpha 5 chain \\
\hline rna8510 & ABTB2 & Ankyrin repeat and BTB domain containing 2 \\
\hline rna5531 ${ }^{a}$ & STAB1 & Stabilin 1 \\
\hline rna2697 & VPS33B & VPS33B late endosome and lysosome associated \\
\hline rna29012 & TRAPPC6A & Trafficking protein particle complex subunit 6A \\
\hline rna44370 & $\mathrm{FMO} 2$ & Flavin containing dimethylaniline monooxygenase 2 \\
\hline rna44593 & PIGR & Polymeric immunoglobulin receptor \\
\hline rna8754 & SAA3 & Serum amyloid A-3 protein \\
\hline rna37493 ${ }^{a}$ & GZMH & Granzyme H \\
\hline
\end{tabular}

${ }^{a}$ Indicates up-regulation in mature milk

b Indicates down-regulation in mature milk

mammary secretory alveolar epithelial cells during lactation [56]. Glucose-6-phosphate transporter SLC37A2 and glucose transporter $S L C 2 A 5$ were identified as DEG for the milk type main effect. Glucose transport across the plasma membrane of mammalian cells is carried out by two distinct processes one of which involves glucose transporters from the GLUT gene family (encoded by $S L C 2 A$ genes) and the other which involves glucose transporters from the $S G L T$ family (encoded by SLC5A genes). Both the SLC2A5 and SLC37A2 genes were up-regulated in colostrum. Crisá et al. [24] identified significant up-regulation of members of the $S L C 2 A$ gene family and polysaccharide and glycosamino-glycan binding molecular function to be enriched in goat colostrum samples compared to mature milk.

Members of the SLC35 gene family encode nucleotide sugar transporters localizing at the Golgi apparatus and/or the endoplasmic reticulum. These transporters transport nucleotide sugars pooled in the cytosol into the lumen of these organelles, where most glycoconjugate synthesis occurs [57]. Currently, the SLC35 gene family is comprised of 31 genes which are divided into 7 subfamilies, SLC35A to SLC35G [58]. GDP-fucose transporters SLC35C1 and $S L C 35 C 2$ were identified as DEG for the milk type main effect, with $S L C 35 C 2$ up-regulated in colostrum and $S L C 35 C 1$ down-regulated. Several other members of the SLC35 family, SLC35B2, SLC35D1, SLC35E1, SLC35E3, and SLC35G1, were statistically significant but were filtered out based on our log-fold change criteria. Crisà et al. [24] identified 3 DEG from the $S L C 35$ family that were up-regulated in goat colostrum compared to mature milk, as well as enrichment of glycosaminoglycan binding molecular in colostrum. Consistent with this result, we also identified the enrichment of glycosaminoglycan binding molecular function, with 22 of the 118 annotated genes associated with the GO term being present in our milk type DEG set. 
Table 6 Twenty-five most significant DET associated with milk type x parity interaction. Significance was ranked using FDR-adjusted $P$-value

\begin{tabular}{|c|c|c|}
\hline Transcript & Gene & Gene Description \\
\hline rna22238 & AHCYL1 & Adenosylhomocysteinase like 1 \\
\hline rna27866 & LOC100621677 & Dipeptidase 3 (DPEP3) \\
\hline MSTRG.208683.14 & GRB10 & Growth factor receptor bound protein 10 \\
\hline rna14076 & POR & P450 (cytochrome) oxidoreductase \\
\hline rna62377 & ANXA7 & Annexin A7 \\
\hline rna69234 & PCM1 & Pericentriolar material 1 \\
\hline MSTRG.337836.10 & EXOC4 & Exocyst complex component 4 \\
\hline rna62750 & ADIRF & Adipogenesis regulatory factor \\
\hline rna69254 & PCM1 & Pericentriolar material 1 \\
\hline rna16978 & EHBP1 & EH domain binding protein 1 \\
\hline MSTRG.114444.62 & LMNTD1 & Lamin tail domain containing 1 \\
\hline rna31913 & PTP4A2 & Protein tyrosine phosphatase $4 \mathrm{~A} 2$ \\
\hline MSTRG.329474.6 & RRBP1 & Ribosomal binding protein 1 \\
\hline MSTRG.86648.4 & PUF60 & Poly(U) binding splicing factor 60 \\
\hline rna56801 & WWTR1 & WW domain containing transcription regulator 1 \\
\hline MSTRG.253426.1 & SELENOT & Selenoprotein $\mathrm{T}$ \\
\hline MSTRG.40523.3 & PDCL & Phosducin like \\
\hline rna50113 & GPS1 & G protein pathway suppressor 1 \\
\hline MSTRG.341587.6 & SCRN1 & Secernin 1 \\
\hline rna77208 & EIF5 & Eukaryotic translation initiation factor 5 \\
\hline MSTRG.290003.24 & GPAM & Glycerol-3-phosphate acyltransferase, mitochondrial \\
\hline MSTRG.266678.8 & NRIP1 & Nuclear receptor interacting protein 1 \\
\hline MSTRG.118470.4 & TXNRD1 & Thioredoxin reductase 1 \\
\hline MSTRG.373117.37 & LOC102158401 & Collagen alpha-1(I) chain-like \\
\hline MSTRG.221153.6 & STARD13 & StAR related lipid transfer domain containing 13 \\
\hline
\end{tabular}

The JAK-STAT pathway regulates lactation [59]. The main gene families in the pathway are Janus kinases $(J A K)$ and the signal transducers and activators of transcription proteins (STAT). Members of the JAK family, JAK1, JAK2, $J A K 3$, and $T Y K 2$, have been linked to cytoplasmic domains of diverse cytokine receptors [60], while members of the STAT family, STAT1-4, STAT5A, STAT5B, and $S T A T 6$, are involved in cell growth, differentiation, apoptosis, and mammary gland development. Members of both families have been associated with bovine milk production [61]. JAK3 was significantly differentially expressed for the milk type main effect, with increased expression in colostrum, while $J A K 2$ was statistically significant but was filtered out of our DEG list due to thresholding on log-fold change (log2 fold change $=1.3$ ). A single nucleotide polymorphism (SNP) in the JAK2 gene has previously been associated with milk, protein, and fat yields in bovine milk production [62].

Twenty-six genes from the PI3K-Akt pathway, which lies within the JAK-STAT pathway, were found to be differentially expressed. The PI3K-Akt pathway is important for the synthesis of lactose and lipids, as well as glucose transport [63]. Although not statistically significant after FDR-correction, this pathway had a nominal $P$-value of 0.029 in the enrichment analysis. The PI3K-Akt pathway is a key signaling node for lactogenic expansion and differentiation of the luminal mammary epithelium, as numerous signaling pathways that regulate lactogenic development converge on PI3K-Akt, including the insulin-like growth factor 1 receptor (IGF1R), RANKL and RANK, integrins, and PRLR-to-JAK2-to-STAT5A pathways [64]. In general, expression of DEG in the PI3K-Akt pathway was up-regulated in colostrum (Fig. 10). The PI3K-Akt pathway was also identified as major pathway enriched in human and bovine colostrum [65].

Several GO terms related to immune response, particularly leukocyte differentiation, leukocyte migration, regulation of immune system process, and humoral immune system process, were significantly enriched in the DEG for the milk type main effect (Tables S11 and S12). 


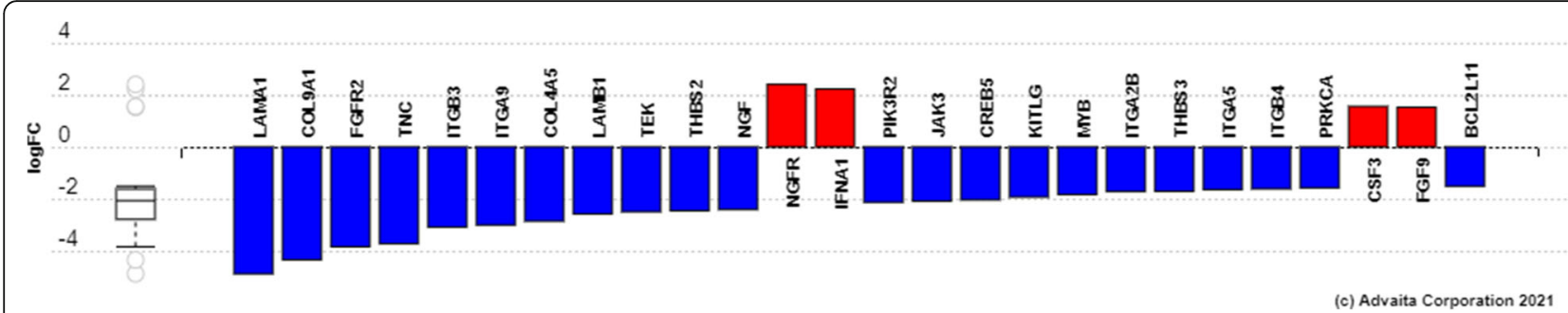

Fig. 10 Log2 fold change (mature milk vs. colostrum) of milk type main effect DEG in the PI3K-AKT signaling pathway. Image was produced by the iPathwayGuide software (Advaita Bio, http://advaitabio.com/ipathwayguide)

Nearly all of the DEG associated with these GO terms were up-regulated in colostrum. This finding is consistent with the immunoglobulins and immune cells being transferred to the neonate via colostrum [66]. In pigs, the epitheliochorial nature of the placenta prohibits transfer of maternal immune cells and immunoglobulins to the fetus, and thus, the piglet relies on the successful absorption of colostral components to acquire maternal immunity [67]. Proinflammatory cytokines play an important role in the development of the neonatal immune system by mediating the early local and systemic responses to microbial challenges [68]. A total of 16 DEG were associated with cytokine secretion, including interleukin 21 receptor $(I L 21 R)$, interleukin 27 receptor A (IL27RA), and tumor necrosis receptor superfamily members 1B (TNFRSF1B). Several other genes in these gene families were shown to be up-regulated in early porcine lactation by Palombo et al. [20]. This was consistent was our findings as all cytokine secretion genes except CD36, CIDEA, F2RL1, TLR6, and BTN1A1 were up-regulated in colostrum (Table S12).

Antimicrobial proteins naturally present in colostrum and milk can kill and inhibit a broad spectrum of bacteria [69]. Milk is also known to exert chemotactic activity on neutrophils [70], an important innate host defense against microorganisms. The chemokine superfamily encodes secreted proteins involved in immunoregulatory and inflammatory processes. The CXC chemokine ligand 14 (CXCL14), which encodes a chemokine antimicrobial protein [71], was up-regulated in colostrum samples (Fig. 11). Many of the other main chemokines (CXCL2, CXCL8, CXCL9, CXCL10, CXCL11, CXCL13, CXC14, and $C X C L 16)$ were expressed in our samples. Interleukin 8/CXC ligand (CXCL8) was the most highly expressed chemokine across our samples. It has also been reported to be highly expressed in human milk [72-74]. In human milk, the expression of $C X C L 8$ was highest in the immediate postpartum period and decreased over the

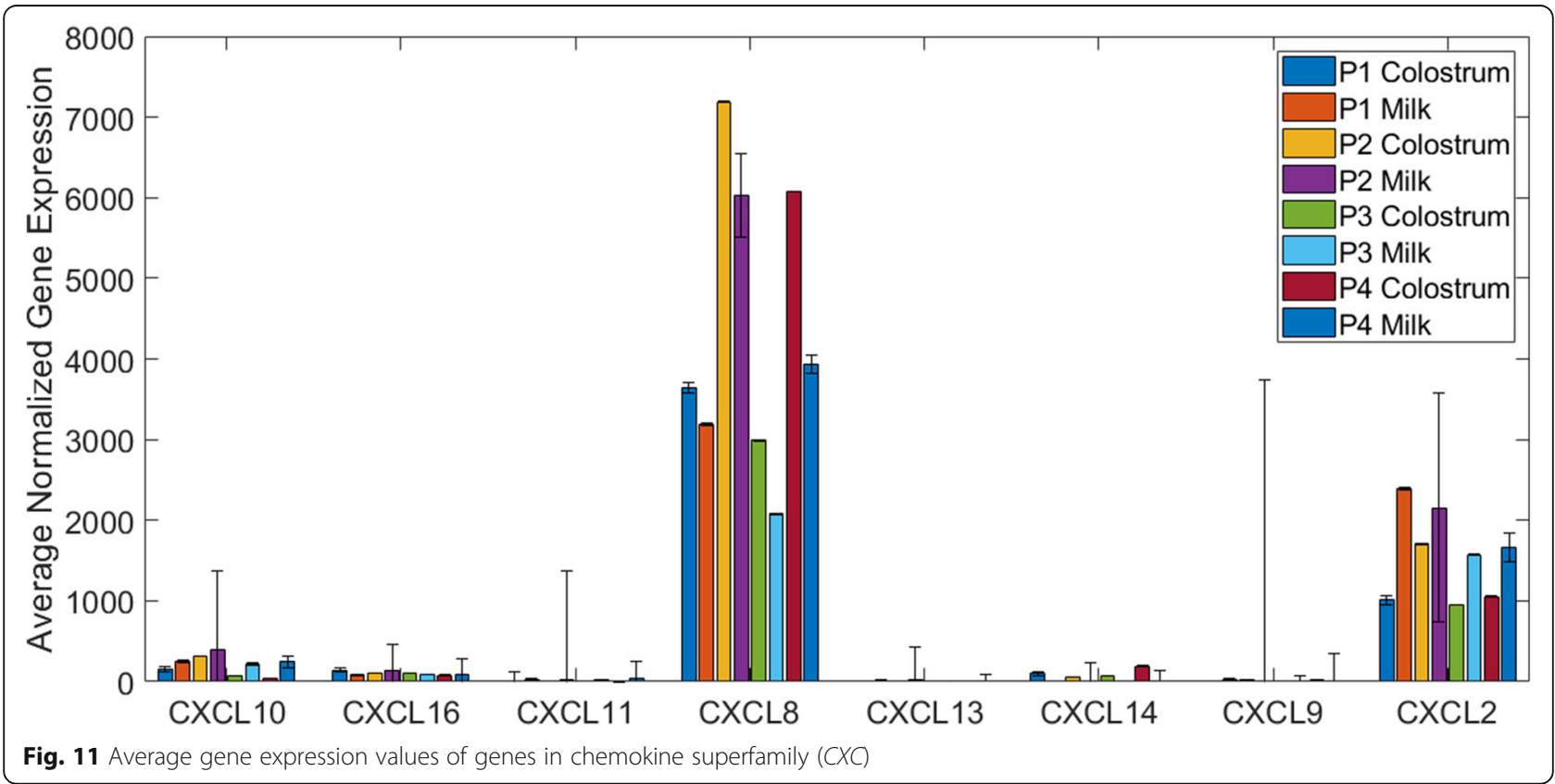


first week of lactation [74]. A similar pattern was observed in our samples, with markedly higher expression of CXCL8 in colostrum compared to mature milk across all parities. The second highest expressed chemokine in our samples was growth-related oncoprotein beta (CXCL2). In parity 1 and parity 3 samples, expression of CXCL2 was higher in mature milk samples $(P=0.0023$ for P1 and $P=0.0160$ for P3; paired T-test). Though not statistically significant, the average expression values for CXCL2 were also higher in mature milk in parities 2 and 4. Although expression of CXCL2 was found to be high in human milk samples, it did not change with time postpartum [74]. In bovine milk samples, it was reported that compared to other chemokines, concentrations of CXCL2 are generally low and decrease sharply after the onset of lactation [70]. Palombo et al. [20] identified significant up-regulation of CXCL2 and CXCL10 in day 1 postpartum swine mammary gland samples compared to mammary samples taken before parturition. We found that both CXCL2 and CXCL1O increased in expression with time postpartum. Our results differed from the results in [20] in that CXCL8 was the most abundantly expressed chemokine in our colostrum and mature milk samples, and CXCL3 was not expressed. One factor contributing to this discrepancy was the use of the improved reference genome (Sscrofa 11.1), where many of the gaps and misassemblies present in the Sscrofa 10.2 genome build were resolved and the annotation was significantly improved. These results suggest that chemokine ligands may play an important role in the transition from colostrum to mature milk in swine, likely helping prompt recruitment of neutrophils.

\section{Conclusions}

Porcine milk and colostrum are complex biofluids that nourish the neonate and protect it from pathogens and disease. Recent research has shown that in addition to the major nutrient components, such as carbohydrates, lipids, and proteins, other bioactive components, including but not limited to exosomes, oligosaccharides, and bacteria, are present in porcine milk. Understanding both the nutritional and non-nutritional components of porcine milk is essential for improved pig production. Some vital questions that need to be addressed are: 1) What is the sow's genetic contribution to milk composition? 2) What bacteria are present in the mammary gland, milk, and piglet gut, and what is the source of these bacteria? 3) Do different milk oligosaccharide profiles contribute to the microbiome and immunity in the piglet GI tract? This study is a subset of a larger study aimed at addressing these questions. Our findings have produced several highly specialized and functional candidate genes that may contribute to postnatal development and growth of piglets, as well as lactation in the sow. A deeper understanding of these genes could provide a coherent approach to genetically regulate milk composition in the future.

\section{Methods \\ Population and sampling}

A four-breed composite line (Maternal Landrace $\times$ High-lean Landrace $\times$ Duroc $\times$ Yorkshire) maintained at the U.S. Meat Animal Research Center (USMARC) for at least 18 generations was used for the collection of data in this project and has been previously described $[75,76]$. Litter sizes were adjusted within $48 \mathrm{~h}$ of farrowing to ensure litters were approximately equal in size but did not exceed the number of functional teats. Mammary excretion samples were collected on day of farrowing (d 0; colostrum) and again on day 10 post-farrowing (d 10; mature milk) from a total of 65 dams, 16 first parity (P1), $25 \mathrm{~s}$ parity (P2), 15 third parity (P3), and 9 fourth parity (P4). The power calculation for this experiment was conducted using the online RNASeqSampleSize tool ([77]; http://cqs.mc.vanderbilt.edu/shiny/ RnaSeqSampleSize/). The power of using 65 animals to detect $\sim 1000$ DEG, with maximum dispersion 0.5 and minimum fold change of 2.82, at FDR level 0.05 from 17,740 expressed genes was found to be 0.99 . After sample collection, animals remained at USMARC and progressed through the breeding system according to standard operating procedures.

In most cases, no external stimulant (i.e., oxytocin) was needed to collect colostrum at time of farrowing, as farrowing stimulates endogenous oxytocin production and milk letdown activity. However, if enough colostrum could not be collected within $10-30 \mathrm{~min}$, an intramuscular injection of oxytocin (20 IU) was administered to stimulate colostrum letdown. Teats were sprayed with iodine $(5 \%)$ and ethanol (70\%) and wiped clean with a chem-wipe, and then $10 \mathrm{~mL}$ of colostrum was collected manually from the third and fourth teat on one side of the sow. On $d 10$, piglets were separated from the sow for approximately $1 \mathrm{~h}$, and sows were given an intramuscular injection of $20 \mathrm{IU}$ oxytocin to stimulate milk letdown. Teats were cleaned, and $10 \mathrm{~mL}$ of milk was collected manually from the third and fourth teat on one side of the sow. Fresh samples were transported to the laboratory on ice. Samples $(250 \mu \mathrm{L})$ were aliquoted into individual lysis D matrix tubes (MP Biomedicals, LLC, Solon, $\mathrm{OH}$ ) with $1 \mathrm{~mL}$ TRIzol reagent (Invitrogen, Thermo Fisher Scientific, Waltham, MA) and stored at $-80^{\circ} \mathrm{C}$ until RNA isolation.

\section{RNA isolation and sequencing}

RNA was isolated using the FastPrep-24 5G Instrument (MP Biomedicals, LLC) with cryogenic lysis. Briefly, RNA was isolated by high-speed cellular disruption 
using multi-directional, simultaneous bead beating of sample material (i.e., colostrum or milk) with a cool adapter for cryogenic lysis at $6.0 \mathrm{~m} / \mathrm{sec}$ for $40 \mathrm{~s}$. Lysed samples were transferred into a clean tube, and completion of isolation occurred following manufacturer's recommended protocol for TRIzol. The final RNA pellet was dried at RT for $10 \mathrm{~min}$ and resuspended in $30 \mu \mathrm{L}$ water (Invitrogen UltraPure DNase/RNase-free, Thermo Fisher Scientific). RNA was quantified using a NanoDrop UV-Vis spectrophotometer (Thermo Fisher Scientific) and RNA integrity was assessed using an Agilent Bioanalyzer System (Agilent, Santa Clara, CA).

Total RNA samples extracted from colostrum or milk were prepared for RNA sequencing with the TruSeq Stranded Total RNA with Ribo-Zero Gold sample preparation kit (Illumina, San Diego, CA) following the guidelines of the manufacturer. Libraries were quantified with RT-qPCR using the NEBNext Library Quant Kit (New England Biolabs, Inc., Beverly, MA, USA) on a CFX384 thermal cycler (Bio-Rad, Hercules, CA, USA), and the size and quality of the library was evaluated with an Agilent Bioanalyzer DNA 1000 kit (Santa Clara, CA, USA). The libraries were diluted to $4 \mathrm{nM}$ with Illumina RSB. Libraries were paired-end sequenced with 150 cycle high output sequencing kits on an Illumina NextSeq 500 instrument.

\section{Processing RNA-Seq data}

Alignment of RNA-Seq reads was carried out as follows. First, quality of the raw paired-end sequence reads in individual fastq files was assessed using FastQC (Version 0.11.5; www.bioinformatics.babraham.ac.uk/projects/ fastqc), and reads were trimmed to remove adapter sequences and low-quality bases using the Trimmomatic software (Version 0.35) [78]. The remaining reads were mapped to the Sscrofa 11.1 genome assembly (NCBI accession AEMK00000000.2) using Hisat2 (Version 2.1.0) [79] with default parameters.

Mapped transcripts were assembled for each library using Stringtie (Version 1.3.3) [80]. The NCBI Sscrofa 11.1 reference annotation (Release 106) was used to guide the assembly process. Transcripts from all samples were merged using Stringtie merge mode to build a consensus set of transcripts.

\section{Identification and characterization of novel transcripts}

Transcript expression levels were quantified for each library using fragments per kilobase of exon per million mapped reads (FPKM) [81]. Transcripts expressed in a single sample, and transcripts with FPKM $<0.3$ in all samples were removed. Gffcompare (Version 0.11.2) [82] was used to compare the list of assembled transcripts with the $S$. scrofa reference annotation (NCBI Release 106). Transcripts overlapping known transcript classes in the reference annotation (gffcompare class code ' $=$ ') were assigned to the appropriate annotation class, while transcripts with gffcompare class codes ' $x$ ' (exonic overlap on the opposite strand), 'i' (fully contained in reference intron), ' $j$ ' (multi-exon with at least one junction match), and ' $u$ ' (unknown, intergenic) were considered to be potential novel transcripts.

A modified version of the discovery pipeline described in Cai et al. [83] was used to further filter transcripts and classify novel transcripts (Fig. 2): (i) Filter out transcripts with short lengths $(<200 \mathrm{bp})$ and single exons; (ii) ORF obtained using TransDecoder (Version 5.5.0; https://github.com/TransDecoder/TransDecoder/wiki).

Transcripts with no predicted ORF were filtered out, and transcripts ORF length $\geq 120$ amino acids were considered protein-coding. (iii) Protein coding potential assessed using CPC2 (Version 2.0) [84], PLEK (Version 1.2) [85], and CNIT [86]; (iv) Transcripts were translated to amino acid sequences using the Transeq utility from EMBOSS (https://www.ebi.ac.uk/Tools/st/emboss_ transeq/), and HMMER [87] was used to search for known protein domains against the Pfam database (Release 33.1) [88]. Transcripts with significant Pfam hits (E-value <10.0) were classified as protein-coding. After steps (iii) and (iv), transcripts with no significant Pfam hits, CPC2 classification "coding", PLEK score $>0$, and CNIT $>0$ were classified as protein-coding, and transcripts with no significant Pfam hits, CPC2 classification "noncoding", PLEK score $<0$, and CNIT score $<0$ were classified as non-coding. All other transcripts were discarded, as their coding potential was ambiguous.

The BLASTN algorithm from the BLAST+ package [89] was used to identify homology between (1) novel lncRNA and the NONCODE database (Version 5) and (2) novel mRNA and the NCBI Non-redundant Nucleotide database (nt; Version 5, https://ftp.ncbi.nlm.nih.gov/ blast/db/). BLASTN was run with default parameters, and an E-value cutoff of 10.0 was used to define homologous sequences.

\section{Differential expression and functional analyses}

Raw read counts for the 70,841 transcripts and the 17,910 corresponding genes were normalized using DESeq2 (Version 1.26) [90]. Gene expression distributions were computed for colostrum and mature milk samples by averaging the normalized expression values across samples. The PCA plot, using variance stabilizing transform of normalized read counts, was generated using the plotPCA function from the DESeq2 package. Differential expression analysis of transcripts was performed using DESeq2 with the following generalized linear model: 


$$
Y=\text { Type }+ \text { Parity }+ \text { Type } x \text { Parity } .
$$

Transcripts with FDR-adjusted $P$-value $\leq 0.01$ were considered DET for the type $\mathrm{x}$ parity interaction. Transcripts that were not DET for the interaction term with FDR-adjusted $P$-value $\leq 0.01$ were considered DET for the parity main effect. Transcripts that were not DET for the interaction term with $\mid \log 2$ fold change $\mid \geq 2$ and FDR-adjusted $P$-value $\leq 0.01$ were considered DET for the milk type main effect.

Transcript $P$-values were aggregated for each gene using the Lancaster method [91] to generate gene-level analysis. This approach has been described in detail by Yi et al. [55]. Briefly, the Lancaster method is an extension of the Fisher method [92] for P-value aggregation, where under the null hypothesis that all genes have zero effect, the test statistic $T=\sum_{i=1}^{K} \phi_{w_{i}}^{-1}\left(p_{i}\right)$ follows a chisquared distribution with $d f=\sum_{i=1}^{K} w_{i}$. Here, $K$ denotes the number of transcripts associated with the gene, $w_{1}$, $\ldots, w_{K}$ a set of weights for the transcript $P$-values $p_{1}, \ldots$ $p_{K}$, and $\phi_{w_{i}}^{-1}$ the inverse CDF of the gamma distribution with shape parameter $\alpha_{i}=\frac{w_{i}}{2}$ and scale parameter $\beta=2$. Here, the baseMean parameter from the DESeq2 output was used as $w_{i}$ in the Lancaster method. Aggregated $P$ values were corrected using the Benjamini-Hochberg method. Genes with FDR-adjusted $P$-value $\leq 0.01$ were considered DEG. DEG for the milk type $\mathrm{x}$ parity interaction were removed from the milk type main effect DEG set. Log2-fold changes ( $\log 2 \mathrm{FC}$; mature milk vs. colostrum) were computed for each of the genes using DESeq2, and genes with $|\log 2 \mathrm{FC}| \leq 1.5$ were filtered out of the milk type main effect DEG set.

Enrichment analysis of gene function and cellular pathways was performed for DEG using the iPathwayGuide software (Version 2012; Advaita Bio, http:// advaitabio.com/ipathwayguide) with the default $M$. musculus data as background. For GO analysis, an overrepresentation test, based on a hypergeometric distribution, was used to compute the statistical significance of observing more than the expected number of DEG. A GO term was considered statistically significant at FDRcorrected $P \leq 0.05$. Pathway over-representation analysis was performed by comparing the number of affected genes associated with a pathway between groups. Pathways were considered statistically significant at FDRcorrected $P \leq 0.05$.

\section{Abbreviations}

IgG: Immunoglobin; RNA: Ribonucleic acid; NGS: Next-generation sequencing; MEC: Milk epithelial cells; IncRNA: Long non-coding RNA; bp: Base pairs; RNA-Seq: RNA-sequencing; DEG: Differentially expressed gene; mRNA: Messenger RNA; miRNA: Micro RNA; miscRNA: Miscellaneous small non-coding RNA; circRNA: Circular RNA; ncRNA: Non-coding RNA; ORF: Open reading frame; lincRNA: Long intergenic non-coding RNA; ilncRNA: Identified unknown long non-coding RNA; IncNAT: Long non-coding natural antisense transcripts; isolncRNA: Novel isoform non-coding RNA; SNP: Single nucleotide polymorphism; PCA: Principal component analysis; DET: Differentially expressed transcript; GO: Gene ontology; USMARC: U.S. Meat Animal Research Center; NCBI: National Center for Biotechnology Information; SRA: Sequence Read Archive; FPKM: Fragment per kilobase of exon per million mapped reads

\section{Supplementary Information}

The online version contains supplementary material available at https://doi. org/10.1186/s12863-021-00980-5.

Additional file 1: Table S1. Sequencing statistics. Number of raw sequence reads, number of reads mapping to the $S$. scrofa 11.1 genome assembly, and percentage of mapped reads for each of the sequenced libraries.

Additional file 2: Table S2. Summary of reads mapping to RNA regions of the swine genome. Number of raw sequence reads mapping to annotated RNA regions in the S. scrofa 11.1 genome assembly. RNA classifications are based on the NCBI S. scrofa annotation (Release 106).

Additional file 3: Table S3. Novel IncRNA annotation. Annotation is given in GTF format. LincRNA denotes intergenic IncRNA, ilncRNA denotes intronic RNA, IncNAT denotes natural antisense IncRNA, and isolncRNA denotes novel isoform IncRNA.

Additional file 4: Table S4. Novel mRNA annotation. Annotation is given in GTF format.

Additional file 5: Table S5. BLAST search results for novel IncRNA against NONCODE databases. BLAST hits for novel IncRNA searched against NONCODE databases for multiple species. Entries in the species column indicate the top BLAST hit for the transcript in the given species.

Additional file 6: Table S6. Analysis of differentially expressed transcripts (DET) for the milk type $x$ parity interaction. DET are highlighted in blue.

Additional file 7: Table S7. Analysis of differentially expressed transcripts (DET) for the milk type main effect. DET are highlighted in blue. Transcripts colored gray were filtered out for being significant for the milk type $x$ parity interaction or for having $\mid \log 2$ fold change $\mid<2$. Log2 fold change is for milk vs. colostrum comparison.

Additional file 8: Table S8. Analysis of differentially expressed transcripts (DET) for the parity main effect. DET are highlighted in blue. Transcripts colored gray were filtered out for being significant for the milk type $x$ parity interaction.

Additional file 9: Table S9. Analysis of differentially expressed genes (DEG) for the milk type $x$ parity interaction. DEG are highlighted in blue.

Additional file 10: Table S10. Analysis of differentially expressed genes (DEG) for the milk type main effect. DEG are highlighted in blue. Genes colored gray were filtered out for being significant for the milk type $x$ parity interaction or for having $\mid \log 2$ fold change $\mid<2$. Log2 fold change is for milk vs. colostrum comparison.

Additional file 11: Table S11. Gene ontology (GO) term and pathway analysis for the milk type main effect. Biological process (BP), molecular function (MF), cellular component (CC), and KEGG pathway results are shown in separate tabs.

Additional file 12: Table S12. Milk type DEG associated with various immune response $\mathrm{GO}$ terms. GO terms are given in separate tabs. DEG associated with the GO term and their log2 fold changes (milk vs colostrum) are shown.

Additional file 13: Figure S1. Number of transcripts falling into each Gffcompare class code based on the NCBI S. scrofa 11.1 reference annotation. For class code definitions see https://ccb.jhu.edu/software/ stringtie/gffcompare.shtml

\section{Acknowledgements}

The authors wish to acknowledge Shanda Watts for her outstanding technical and laboratory assistance; the USMARC Core Laboratory for performing the sequencing; Heather Oeltjen-Bruns and Miguel Cervantes for 
their assistance with sample collection; Mike Judy for assistance with data organization; and the USMARC Swine Operations crew.

\section{Authors' contributions}

BNK, LAR, WTO, and JEW conceived of the study and participated in its design and coordination. All authors were involved in the acquisition of data, and BNK performed data analyses. BNK drafted the manuscript, and ALP, WTO, SAJ, JEW, and LAR contributed to the writing and editing. All authors read and approved the final manuscript.

\section{Funding}

Not applicable.

\section{Availability of data and materials}

Sequence data used in this study was submitted to the National Center for Biotechnology Information Sequence Read Archive (NCBI SRA) with Accession Number PRJNA640341.

\section{Declarations}

\section{Ethics approval and consent to participate}

The U.S. Meat Animal Research Center Animal Care and Use Committee reviewed and approved all animal procedures (Experimental Outline \#100.0). The procedures for handling pigs complied with the Guide for the Care and Use of Agricultural Animals in Agricultural Research and Teaching [93].

\section{Consent for publication}

Not applicable.

\section{Competing interests}

The authors declare that they have no competing interests.

Received: 19 July 2021 Accepted: 29 July 2021

Published online: 10 August 2021

\section{References}

1. Theil PK, Lauridsen C, Quesnel H. Neonatal piglet survival: impact of sow nutrition around parturition on fetal glycogen deposition and production and composition of colostrum and transient milk. Animal. 2014;8(7):102130. https://doi.org/10.1017/\$1751731114000950.

2. Langer $P$. Differences in the composition of colostrum and milk in eutherians reflect differences in immunoglobulin transfer. J Mammal. 2009; 90(2):332-9. https://doi.org/10.1644/08-MAMM-A-071.1.

3. Quesnel H, Farmer C, Theil PK. Colostrum and milk production. Chapter 8. In: Farmer $C$, editor. The gestating and lactating sow. Wageningen: Wageningen Academic Publishers; 2015.

4. Carney-Hinkle EE, Tran H, Bundy JW, Moreno R, Miller PS, Burkey TE. Effect of dam parity on litter performance, transfer of passive immunity, and progeny microbial ecology. J Anim Sci. 2013;91(6):2885-93. https://doi.org/10.2527/ja s.2011-4874.

5. Craig JR, Collins CL, Bunter KL, Cottrell JJ, Dunshea FR, Pluske JR. Poorer lifetime growth performance in gilt progeny compared with sow progeny is largely due to weight differences at birth and reduced growth in the preweaning period, and is not improved by progeny segregation after weaning. J Anim Sci. 2017;95(11):4904-16. https://doi.org/10.2527/jas2017.1868.

6. Craig JR, Dunshea FR, Cottrell JJ, Wijesiriwardana UA, Pluske JR. Primiparous and multiparous sows have largely similar colostrum and milk composition profiles throughout lactation. Animals (Basel). 2019;9(2):35

7. Boutinard M, Jammes $H$. Potential uses of milk epithelial cells:a review. Reprod Nutr Dev. 2002;42(2):133-47. https://doi.org/10.1051/rnd:2002013.

8. Weber JA, Baxter DH, Zhang S, Huang DY, Huang KH, Lee MJ, et al. The MicroRNA spectrum in 12 body fluids. Clin Chem. 2010;56(11):1733-41. https://doi.org/10.1373/clinchem.2010.147405

9. Golan-Gerstl R, Shiff YE, Moshayoff V, Schecter D, Leshkowitz D, Reif S. Characterization and biological function of milk-derived miRNAs. Mol Nutr Food Res. 2017;61(10):1700009. https://doi.org/10.1002/mnfr.201700009.

10. Lemay DG, Ballard OA, Hughes MA, Morrow AL, Horseman ND, NommsenRivers L. RNA sequencing of the human milk fat layer transcriptome reveals distinct gene expression profiles at three stages of lactation. PLoS One. 2013a;8(7):e67531. https://doi.org/10.1371/journal.pone.0067531.
11. Zeng B, Chen T, Xie MY, Luo JY, He JJ, Xi QY, et al. Exploration of long noncoding RNA in bovine milk exosomes and their stability during digestion in vitro. J Dairy Sci. 2019;102(8):6726-37. https://doi.org/10.3168/ jds.2019-16257.

12. Zeng B, Chen T, Luo J, Xie M, Wei M, Xi Q, et al. Exploration of long noncoding RNAs and circular RNAs in porcine milk exosomes. Front Genet. 2020;11:652. https://doi.org/10.3389/fgene.2020.00652.

13. Harmon B. Somatic cell counts: a primer. Annual Meeting-National Mastitis Council Incorporated, National Mastitis Council, vol. 40; 2001

14. de la Torre GC, Goreham RV, Bech Serra JJ, Nann T, Kussman M. "Exosomics" - a review of biophysics, biology and biochemistry of exosomes with focus on human breast milk. Front Genet. 2018;9:92.

15. Chen $T$, Xie M, Sun J, Ye R, Cheng $X$, Sun $R$, et al. Porcine milk-derived exosomes promote proliferation of intestinal epithelial cells. Nat Sci Rep. 2016:6(1):33862. https://doi.org/10.1038/srep33862.

16. Izumi H, Kosaka N, Shimizu T, Sekine K, Ochiya T, Takase M. Bovine milk contains microRNA and messenger RNA that are stable under degradative conditions. J Dairy Sci. 2012;95(9):4831-41. https://doi.org/10.3168/jds.20125489.

17. Rani P, Yenuganti VR, Shandilya S, Onteru SK, Singh D. miRNAs: the hidden bioactive component of milk. Trends food Sci. Technol. 2017;65:94-102.

18. Izumi H, Tsuda M, Sato Y, Kosaka N, Ochiya T, Iwamoto $H$, et al. Bovine milk exosomes contain microRNA and mRNA and are taken up by human macrophages. J Dairy Sci. 2015;98(5):2920-33. https://doi.org/10.3168/jds.2 014-9076.

19. Zhao W, Shahzad K, Jiang M, Graugnard DE, Rodriguez-Zas SL, Luo J, et al. Bioinformatics and gene network analyses of the swine mammary gland transcriptome during late gestation. Bioinform Biol Insights. 2013;7:193-216. https://doi.org/10.4137/BBI.S12205.

20. Palombo V, Loor JJ, D’Andrea M, Vailati-Riboni M, Shahzad K, Krogh U, et al. Transcriptional profiling of swine mammary gland during the transition from colostrogenesis to lactogenesis using RNA sequencing. BMC Genomics. 2018;19(1):322. https://doi.org/10.1186/s12864-018-4719-5.

21. Wickramasinghe S, Hua S, Rincon G, Islas-Trejo A, German JB, Lebrilla CB, et al. Transcriptome profiling of bovine milk oligosaccharide metabolism genes using RNA-sequencing. PLoS One. 2011;6(4):e18895. https://doi.org/1 0.1371/journal.pone.0018895

22. Medrano JF, Rincon G, Islas-Trejo A. Comparative analysis of bovine milk and mammary gland transcriptome using RNA-Seq, In 9th world congress in genetics applied to livestock production, Leipzig, Germany; 2010. p. 852.

23. Wickramasinghe S, Rincon G, Islas-Trejo A, Medrano JF. Transcriptional profiling of bovine milk using RNA sequencing. BMC Genomics. 2012;13(1): 45. https://doi.org/10.1186/1471-2164-13-45.

24. Crisà A, Ferrè F, Chillemi G, Moioli B. RNA-sequencing for profiling goat milk transcriptome in colostrum and mature milk. BMC Vet Res. 2016;12(1):264. https://doi.org/10.1186/s12917-016-0881-7.

25. Suárez-Vega A, Gutiérrez-Gil B, Klopp C, Robert-Granie C, Tosser-Klopp G, Arranz JJ. Characterization and comparative analysis of the milk transcriptome in two dairy sheep breeds using RNA sequencing. Nat Sci Rep. 2015;5:18399.

26. Arora R, Sharma A, Sharma U, Girdhar Y, Kaur M, Kapoor P, et al. Buffalo milk transcriptome: a comparative analysis of early, mid and late lactation. Nat Sci Rep. 2019:9(1):5993. https://doi.org/10.1038/s41598-019-42513-2.

27. Lemay DG, Hovey RC, Hartono SR, Hinde K, Smilowitz JT, Ventimiglia F, et al. Sequencing the transcriptome of milk production: milk trumps mammary tissue. BMC Genomics. 2013b;14(1):872. https://doi.org/10.1186/1471-21 64-14-872.

28. Wang $Y$, Li D, Wang Y, Li M, Fang $X$, Chen $H$, et al. The landscape of circular RNAs and mRNAs in bovine milk exosomes. J Food Comp Anal. 2019:76:338. https://doi.org/10.1016/j.jfca.2018.12.004.

29. Chen T, Xi Q, Sun J, Ye R, Cheng X, Sun R, et al. Revelation of mRNAs and proteins in porcine milk exosomes by transcriptomic and proteomic analysis. BMC Vet Res. 2017;13(1):101. https://doi.org/10.1186/s12917-017-1 021-8.

30. Witkowska-Zimny M, Kaminska-El-Hassan E. Cells of human breast milk. Cell Mol Biol. 2017:22:11.

31. Zlotnik I. Types of cells present in cow's milk. J Comp Pathol Ther. 1947;57: 196-208, https://doi.org/10.1016/S0368-1742(47)80025-6.

32. Zhang S, Chen F, Zhang Y, LV Y, Heng J, Min T, et al. Recent progress of porcine milk components and mammary gland function. J Ani Sci Biotech. 2018;9(1):77. https://doi.org/10.1186/s40104-018-0291-8. 
33. Alsaweed M, Hepworth AR, Lefèvre C, Hartmann PE, Geddes DT, Hassiotou F. Human milk microRNA and total RNA differ depending on milk fractionation. J Cell Biochem. 2015;116(10):2397-407. https://doi.org/10.1 002/jcb.25207.

34. Li R, Dudemaine PL, Zhao X, Lei C, Ibeagha-Awemu EM. Comparative analysis of the miRNome of bovine milk fat, whey and cells. PLoS One. 2016;11(4):e0154129. https://doi.org/10.1371/journal.pone.0154129.

35. Huston GE, Patton S. Factors related to the formation of cytoplasmic crescents on milk fat globules. J Dairy Sci. 1990;73(8):2061-6. https://doi. org/10.3168/jds.S0022-0302(90)78885-6.

36. Munch EM, Harris RA, Mohammad M, Benham AL, Pejerrey SM, Showalter L, et al. Transcriptome profiling of microRNA by next-gen deep sequencing reveals known and novel miRNA species in the lipid fraction of human breast milk. PLoS One. 2013;8(2):e50564. https://doi.org/10.1371/journal. pone.0050564

37. Mortazavi A, Williams BA, Mccue K, Schaeffer L, Wold B. Mapping and quantifying mammalian transcriptomes by RNA-Seq. Nat Methods. 2008:5:1-8.

38. Woliński J, Slupecka-Ziemilska M, Romanowicz K. Leptin and ghrelin levels in colostrum, milk and blood plasma of sows and pig neonates during the first week of lactation. Anim Sci J. 2013;85:2.

39. Ilcol YO, Hizli ZB, Ozkan T. Leptin concentration in breat milk and its relationship to duration of lactational and hormonal status. Int Breastfeed J. 2006;1(1):21. https://doi.org/10.1186/1746-4358-1-21.

40. Pinotti L, Rosi F. Leptin in bovine colostrum and milk. Horm Metab Res. 2006;38(2):89-93. https://doi.org/10.1055/s-2006-925119.

41. Li S, Zhang L, Zhou Q, Jiang S, Yang Y, Cao Y. Characterization of stem cells and immune cells in preterm and term mother's milk. J Hum Lact. 2019; 35(3):528-34. https://doi.org/10.1177/0890334419838986

42. Canovas A, Rincon G, Bevilacqua C, Islas-Trejo A, Brenaut P, Hovey RC, et al. Comparison of five different RNA sources to examine the lactating bovine mammary gland transcriptome using RNA-sequencing. Nat Sci Rep. 2014;4: 5297.

43. Su Z, Dong X, Zhang B, Zeng Y, Fu Y, Yu J, et al. Gene expression profiling in porcine mammary gland during lactation and identification of breedand developmental-stage-specific genes. Sci China Series C. 2006;49(1):2636. https://doi.org/10.1007/s11427-005-0181-0.

44. Cordero G, Isabel B, Morales J, Menoyo D, Piñero C, Daza A, et al. Conjugated linoleic acid (CLA) during last week of gestation and lactation alters colostrum and milk fat composition and performance of reproductive sows. Anim Feed Sci Tech. 2011;168(3-4):232-40. https://doi.org/10.1016/j.a nifeedsci.2011.04.085.

45. Bionaz M, Loor JJ. ACSL1, AGPAT6, FABP3, LPIN1, and SLC27A6 are the most abundant isoforms in bovine mammary tissue and their expression is affected by stage of lactation. J Nutr. 2008a;139:1019-24.

46. Suburu J, Shi L, Wu JJ, Wang S, Samuel M, Thomas MK, et al. Fatty acid synthase is required for mammary gland development and milk production during lactation. Am Physiol-Endoc M. 2014;306:E1132-43.

47. Tansey JT, Sztalryd C, Hlavin EM, Kimmel AR, Londos C. The central role of perilipin a in lipid metabolism and adipocyte lipolysis. IUBMB Life. 2004; 56(7):379-85. https://doi.org/10.1080/15216540400009968.

48. Martel PM, Bingham CM, McGraw CJ, Baker CL, Morganelli PM, Meng ML, et al. S14 protein in breast cancer cells by SREBP-1C, superinduction with progestin, and effects on cell growth. Exp Cell Res. 2006;312:278-88.

49. Yao DW, Luo J, He QY, Wu M, Shi HB, Wang H, et al. Thyroid hormone responsive (THRSP) promotes the synthesis of medium-chain fatty acids in goat mammary epithelial cells. J Dairy Sci. 2016;99(4):3124-33. https://doi. org/10.3168/jds.2015-10632.

50. Bionaz M, Loor JJ. Gene networks driving bovine milk fat synthesis during the lactation cycle. BMC Genomics. 2008b;9(1):366. https://doi.org/10.11 86/1471-2164-9-366

51. Klobasa F, Werhahn E, Butler JE. Composition of sow milk during lactation. J Anim Sci. 1987;64(5):1458-66. https://doi.org/10.2527/jas1987.6451458x.

52. Jensen PT, Pedersen KB. Studies on immunoglobulins and trypsin inhibitor in colostrum and milk from sows and serum in their piglets. Acta Vet Scand. 1979;20(1):60-72. https://doi.org/10.1186/BF03546630.

53. Dawson HD, Loveland JE, Pascal G, Gilbert JGR, Uenishi H, Mann KM, et al. Structural and functional annotation of the porcine immunome. BMC Genomics. 2013;14(1):332. https://doi.org/10.1186/1471-2164-14-332.

54. Twigger AJ, Küffer GK, Geddes DT. Filgueria L. Nutrients. 2018;10(9):1230. https://doi.org/10.3390/nu10091230.
55. Yi L, Pimentel H, Bray NL, Pachter L. Gene-level differential analysis at transcript-level resolution. Genome Biol. 2018;19(1):53. https://doi.org/10.11 86/s13059-018-1419-z.

56. Zhao FQ. Biology of glucose transport in the mammary gland. J Mammary Gland Biol Neoplasia. 2014;19(1):3-17. https://doi.org/10.1007/s10911-0139310-8.

57. Ishida N. Kawakita. Molecular physiology and pathology of the nucleotide sugar transporter family (SLC35). Eur J Phys. 2004;447(5):768-75. https://doi. org/10.1007/s00424-003-1093-0.

58. Song Z. Roles of the nucleotide sugar transporters (SLC35 family) in health and disease. Mol Asp Med. 2013;34(2-3):590-600. https://doi.org/10.1016/j. mam.2012.12.004

59. Bionaz M, Loor JJ. Gene networks driving bovine mammary protein synthesis during the lactation cycle. Bioinfom Biol Insights. 2011;5:83-98.

60. Liongue C, Ward AC. Evolution of the JAK-STAT pathway. JAKSTAT. 2013;2: e22756.

61. Khan MZ, Khan A, Xiao J, Ma Y, Ma J, Gao J, et al. Rols of JAK-STAT pathway in bovine mastitis and milk production. Animals (Basel). 2020;10(11):2107.

62. Szewczuk M. Association of a genetic marker at the bovine Janus kinase 2 locus (JAK2/Rsal) with milk production traits in four cattle breeds. J Dairy Res. 2015;82(3):287-92. https://doi.org/10.1017/S0022029915000291.

63. Oliver CH, Watson CJ. Making milk. JAKSTAT. 2013;2:2.

64. Williams MM, Vaught DB, Joly MM, Hicks DJ, Sanchez V, Owens P, et al. ErbB3 drives mammary epithelial survival and differentiation during pregnancy and lactation. Breast Cancer Res. 2017;19(1):105. https://doi.org/1 0.1186/s13058-017-0893-7.

65. Cao X, Zheng Y, Wu S, Yang N, Wu J, Liu B, et al. Characterization and comparison of milk fat globule membrane glycoproteomes from human and bovine colostrum and mature milk. Food Funct. 2019;10(8):5046-58. https://doi.org/10.1039/C9FO00686A.

66. Rooke JA, Bland IM. The acquisition of passive immunity in the newborn piglet. Livest Prod Sci. 2002;1(28):13-23.

67. Bandrick M, Ariza-Nieto C, Baidoo SK, Molitor TW. Colostral antibodymediated and cell-mediated immunity contributes to innate and antigenspecific immunity in piglets. Dev Comp Immunol. 2014;43(1):114-20. https:// doi.org/10.1016/j.dci.2013.11.005

68. Nguyen TV, Yuan L, Azevedo MSP, Jeong K, Gonzalez A-M, Saif LJ. Transfer of maternal cytokines to suckling piglets: in vivo and in vitro models with implications for immunomodulation of neonatal immunity. Vet Immunol Immunopathol. 2007;117(3-4):236-48. https://doi.org/10.1016/j.vetimm.2007. 02.013

69. Hurley WL, Theil PK. Perspectives on immunoglobulins in colostrum and milk. Nutrients. 2011;3(4):442-74. https://doi.org/10.3390/nu3040442.

70. Rainard P, Riollet C, Berthon P, Cunha P, Fromageau A, Rossignol C, et al. The chemokine CXCL3 is responsible for the constitutive chemotactic activity of bovine milk for neutrophils. Mol Immunol. 2008;45(15):4020-7. https://doi.org/10.1016/j.molimm.2008.06.010.

71. Lu J, Chatterjee M, Schmid H, Beck S, Gawaz M. CXCL14 as an emerging immune and inflammatory modulator. J Inflamm. 2016:13(1):1. https://doi. org/10.1186/s12950-015-0109-9.

72. Michie CA, Tantscher E, Schall T, Rot A. Physiological secretion of chemokines in human breast milk. Eur Cytokine Netw. 1998;9(2):123-9.

73. Srivastava MD, Srivastava A, Brouhard B, Saneto R, Groh-Wargo S, Kubit J. Cytokines in human milk. Res Commun Mol Pathol Pharmacol. 1996;93:263-8.

74. Maheshwari A, Christensen RD, Calhoun DA. ELR ${ }^{+}$CXC chemokines in human milk. Cytokine. 2003;24(3):91-102. https://doi.org/10.1016/j.cyto.2003. 07.002 .

75. Rempel LA, Freking BA, Miles JR, Nonneman DJ, Rohrer GA, Schneider JF, et al. Association of porcine heparanase and hyaluronidase 1 and 2 with reproductive and production traits in landrace-Duroc-Yorkshire population. Front Genet. 2011;2:20

76. Rempel LA, Vallet JL, Lents CA, Nonneman DJ. Measurements of body composition during late gestation and lactation in first and second parity sows and its relationship to piglet production and post-weaning reproductive performance. Livestock Sci. 2015;178:289-95. https://doi.org/1 0.1016/j.livsci.2015.05.036.

77. Zhao S, Li Cl, Guo Y, Sheng Q, Shyr Y. RNASeqSampleSize: real data based sample size estimation for RNA sequencing. BMC Bioinformatics. 2018;19(1):1-8.

78. Bolger AM, Lohse M, Usadel B. Trimmomatic: a flexible trimmer for Illumina sequence data. Bioinformatics. 2014;30(15):2114-20. https://doi.org/10.1093/ bioinformatics/btu170. 
79. Kim D, Langmead B, Salzberg SL. HISAT: a fast spliced aligner with low memory requirements. Nat Meth. 2015;12(4):357-60. https://doi.org/10.1038/ nmeth.3317.

80. Pertea M, Pertea GM, Antonescu CM, Chang TC, Mendell JT, Salzberg SL. StringTie enables improved reconstruction of a transcriptome from RNA-seq reads. Nat Biotech. 2015;33(3):290-5. https://doi.org/10.1038/nbt.3122.

81. Lee S, Seo CH, Lim B, Yang JO, Oh J, Kim M, et al. Accurate quantification of transcriptome from RNA-Seq data by effective length normalization. Nucleic Acids Res. 2011;39(2):e9. https://doi.org/10.1093/nar/gkq1015.

82. Pertea M, Kim D, Pertea G, Leek JT, Salzberg SL. Transcript-level expression analysis of RNA-seq experiments with HISAT, StringTie, and Ballgown. Nat Protoc. 2016;11(9):1650-67. https://doi.org/10.1038/nprot.2016.095.

83. Cai W, Li C, Liu S, Zhou C, Yin H, Song J, et al. Genome wide identification of novel long non-coding RNAs and their potential associations with milk proteins in Chinese Holstein cattle. Front Genet. 2018;9:281. https://doi.org/1 0.3389/fgene.2018.00281.

84. Kang YJ, Yang DC, Kong L, Hou M, Meng YQ, Wei L, et al. CPC2: a fast and accurate potential calculator based on sequence intrinsic features. Nucleic Acids Res. 2017;45(W1):W12-6. https://doi.org/10.1093/nar/gkx428.

85. Li A, Zhang J, Zhou Z. PLEK: a tool for predicting long non-coding RNAs and messenger RNAs based on an improved k-mer scheme. BMC Bioinformatics. 2014;15(1):311. https://doi.org/10.1186/1471-2105-15-311.

86. Guo JC, Fang SS, Wu Y, Zhang JH, Chen Y, Liu J, et al. CNIT: a fast and accurate web tool for identifying protein-coding and long non-coding transcripts based on intrinsic sequence composition. Nucleic Acids Res. 2019:47(W1):W516-22. https://doi.org/10.1093/nar/gkz400.

87. Finn RD, Clements J, Eddy SR. HMMER web server: interactive sequence similarity searching. Nucleic Acids Res. 2011;39(suppl):W29-37. https://doi. org/10.1093/nar/gkr367.

88. Finn RD, Coggill P, Eberhardt RY, Eddy SR, Mistry J, Mitchell AL, et al. The Pfam protein families database: towards a more sustainable future. Nucleic Acids Res. 2016;44(D1):D279-85. https://doi.org/10.1093/nar/gkv1344.

89. Camacho C, Coulouris G, Avagyan V, Ma N, Papadopoulos J, Bealer K, et al. BLAST+: architecture and applications. BMC Bioinformatics. 2009;10(1):421. https://doi.org/10.1186/1471-2105-10-421.

90. Love Ml, Huber W, Anders S. Moderated estimation of fold change and dispersion for RNA-seq data with DESeq2. Genome Biol. 2014:12(12):550.

91. Lancaster $\mathrm{H}$. The combination of probabilities: an application of orthonormal functions. Austral J Statist. 1961;3:20-33.

92. Fisher RA. Statistical methods for research workers. Edinburgh: Oliver and Boyd; 1932.

93. McGlone J. Guide for care and use of agricultural animals in agricultural research and teaching. Savoy: Fed. Animal Science Society; 2010.

\section{Publisher's Note}

Springer Nature remains neutral with regard to jurisdictional claims in published maps and institutional affiliations.

Ready to submit your research? Choose BMC and benefit from:

- fast, convenient online submission

- thorough peer review by experienced researchers in your field

- rapid publication on acceptance

- support for research data, including large and complex data types

- gold Open Access which fosters wider collaboration and increased citations

- maximum visibility for your research: over $100 \mathrm{M}$ website views per year

At $\mathrm{BMC}$, research is always in progress.

Learn more biomedcentral.com/submissions 